NBER WORKING PAPER SERIES

\title{
CHARTER SCHOOLS IN NEW YORK CITY: \\ WHO ENROLLS AND HOW THEY AFFECT THEIR STUDENTS' ACHIEVEMENT
}

\author{
Caroline M. Hoxby \\ Sonali Murarka \\ Working Paper 14852 \\ http://www.nber.org/papers/w14852
NATIONAL BUREAU OF ECONOMIC RESEARCH
1050 Massachusetts Avenue
Cambridge, MA 02138
April 2009

This research was sponsored by the United States Department of Education's Institute for Education Sciences under Contract R305A040043. We are grateful to the National Center on School Choice at Vanderbilt University for their support. We are also thankful to the New York City Department of Education, including Lori Mei, Jennifer Bell-Ellwanger, and Janet Brand in particular, for their assistance in providing us with administrative data. The New York City Center for Charter School Excellence and the individual charter schools participating in the study have been indispensable for their cooperation in compiling data. We are thankful for excellent research assistance from Greg Balliro, Jon Choate, Gary Garcia, Wojtek Kubik, Ayah Mahgoub, Daniel Morgan, Elisa Olivieri, John Oxtoby, Mike Schor, and Rebecca Wald. We thank Jonah Rockoff and the members of the NBER Economics of Education program for comments. The views expressed herein are those of the author(s) and do not necessarily reflect the views of the National Bureau of Economic Research.

NBER working papers are circulated for discussion and comment purposes. They have not been peerreviewed or been subject to the review by the NBER Board of Directors that accompanies official NBER publications.

(C) 2009 by Caroline M. Hoxby and Sonali Murarka. All rights reserved. Short sections of text, not to exceed two paragraphs, may be quoted without explicit permission provided that full credit, including (C) notice, is given to the source. 
Charter Schools in New York City: Who Enrolls and How They Affect Their Students' Achievement Caroline M. Hoxby and Sonali Murarka

NBER Working Paper No. 14852

April 2009

JEL No. H0,H42,H75,I2,I21,I22,I28

\begin{abstract}
We analyze all but a few of the 47 charter schools operating in New York City in 2005-06. The schools tend to locate in disadvantaged neighborhoods and serve students who are substantially poorer than the average public school student in New York City. The schools also attract black applicants to an unusual degree, not only relative to New York City but also relative to the traditional public schools from which they draw. The vast majority of applicants are admitted in lotteries that the schools hold when oversubscribed, and the vast majority of the lotteries are balanced. By balanced, we mean that we cannot reject the hypothesis that there are no differences in the observable characteristics of lotteried-in and lotteried-out students. Using the lotteries to form an intention-to-treat variable, we instrument for actual enrollment and compute the charter schools' average treatment-on-the-treated effects on achievement. These are 0.09 standard deviations per year of treatment in math and 0.04 standard deviations per year in reading. We estimate correlations between charter schools' policies and their effects on achievement. The policy with the most notable and robust association is a long school year--as long as 220 days in the charter schools.
\end{abstract}

Caroline M. Hoxby

Department of Economics

Stanford University

Landau Building, 579 Serra Mall

Stanford, CA 94305

and NBER

choxby@stanford.edu

Sonali Murarka

The Wharton School of the University of Pennsylvan

1150 Steinberg Hall-Dietrich Hall

3620 Locust Walk

Philadelphia, PA 19104.6302

murarkas@nber.org 


\section{Introduction to the Analysis of New York City's Charter Schools}

In this article, we analyze which students enroll in New York City's charter schools and how the charter schools affect their achievement. This is the first report aimed at a research audience from a continuing study of the charter schools in the City. We expect that follow-up reports will be available on an annual basis. A non-technical report that covers the same topics as this article but that is aimed at educators and policy makers is available. ${ }^{1}$

We attempt to provide descriptive evidence on the students who apply to charter schools, the students who are offered places at charter schools (usually through lotteries), and the students who actually enroll in and attend charter schools. We compare these students to New York City's overall student population, to students in the traditional public schools from which the charter schools draw, to students who apply to charter schools but are not offered places (the "lotteried-out"), and to students who apply to charter schools but do not enroll (either because they are lotteried-out or because they decide not to attend despite being offered a place). We describe students on the basis of race, ethnicity, their classification for various school-based programs (such as free lunch and special education), and their preapplication test scores (available only for students who had reached at least third grade when they applied). The descriptive evidence just mentioned should help us understand who self-selects into charter schools and how their departure from the traditional public schools affects the population of students enrolled there. However, there are no right answers in this part of the evidence. That is, there is no type of student whom charter schools should or should not enroll given that they are schools whom students are supposed to free to choose or to ignore.

We find that, in practice, charter schools attract students who are disadvantaged relative to New York City's population of public school students. Relative to the students who would likely have been their classmates had they remained in the traditional public schools, charter schools applicants are more likely to be black but are otherwise fairly similar. We are cautious about this last result because, on dimensions other than gender and race, it is not possible to compare the typical charter school applicant to students in the traditional public schools. We explain the need for caution below.

We attempt to estimate the causal effect of the charter schools on their students' test scores, focusing on New York's statewide tests. Our estimation strategy makes use of the fact that the vast majority of charter school students (94 percent of 2005-06 applicants) are admitted via lotteries held among applicants. (A lottery is not held only if a school is undersubscribed. Undersubscription occurs

1 The report aimed for at educators and policy makers can be downloaded from http://www.nber.org/ schools/charterschoolseval. 
most often in a school's start-up year.) We show that lotteried-in and lotteried-out applicants are very similar in a statistical sense. We also show that the vast majority of students who participate in lotteries are in a lottery that is "balanced," meaning that we cannot statistically reject the hypothesis that the lotteried-in and lotteried-out students are the same on all observable characteristics. Lotteries that balance on observable characteristics are also likely to balance on unobservable characteristics such as motivation, which can cause selection bias if left unbalanced. We therefore use students who participated in balanced lotteries to compare post-application test scores of lotteried-in and lotteried-out students. Specifically, we estimate treatment-on-the-treated effects, using the indicator for being lotteried-in to form an intention-totreat instrument for actual enrollment in a charter school. We believe that the resulting estimates are credibly causal effects of attending a New York City charter school relative to the counterfactual of remaining in the traditional public schools from which charter schools draw.

While it is reasonable to extrapolate the findings to other urban students who are similar to New York City applicants, we would argue against these results being extrapolated to students who differ substantially from applicants to the charter schools. In particular, the results should not be extrapolated to students who are substantially more advantaged or to students who would not be interested in applying to the types of charter schools available in New York City, even if they were conveniently located in the students' area. We also note that the counterfactual--that is, the traditional public schools--may be affected by the presence of nearby charter schools. For instance, if traditional public schools improve when faced with competition from charter schools, then lotteried-out students are likely better off than they would have been in the entire absence of charter schools. There is unfortunately nothing we can do to produce a counterfactual that is entirely purged of the influence of charter schools, but we surmise that the charter schools' influence on the counterfactual is still fairly small owing to the small scale of charter school enrollment relative to New York City's public school population.

We find that the causal effect on math test scores in the third through eighth grades is a positive 0.09 standard deviations per year of attendance in a New York City charter school. The parallel causal effect on reading test scores is just about half as large: 0.04 standard deviations per year of attendance in a New York City charter school. These are average effects based on all available student scores. We have thus far observed so few charter school applicants take Regents Examinations that we cannot compute causal effects of charter schools for the examinations in most subjects. For the Math A exam (only), we can compute an estimate, but even this estimate is so imprecise that it is not meaningful.

We expect to be able to describe more interesting results from Regents Examinations in future years as more charter school applicants take the exams.

Because charter schools make independent policy decisions and are independently managed, it is 
reasonable to expect individual schools' effects to vary around the average effects just described and they do. While we do not identify any individual school's effects with its name in this study, we do describe the variation in the effects that we estimate for individual schools. It is important to note that a number of charter schools have thus far had so few test-taking students that we cannot compute the individual school's effects on achievement with enough precision to make the results meaningful. Nevertheless, the test scores of students at such schools are included when we compute the average charter school effects described above.

We use multiple regression in an attempt to identify school policies and practices that are associated with more positive estimated effects on achievement. These associations cannot be interpreted as causal effects because charter schools may adopt policies in response to factors that we do not observe. These unobserved factors may themselves affect achievement. Thus, the regression results reflect correlation, not causation. In addition, schools tend to adopt "packages" of policies, causing a substantial multicollinearity problem. For instance, schools with long school years very often also have long school days. We find statistically significant partial correlations between policy and achievement for only a few individual policies. However, we also find statistically significant partial correlations between certain packages of policies and achievement. All such correlations should be interpreted with caution, not only because they are not causal but also because they are very preliminary. That is, we would not be surprised to find that the correlations change substantially with next year's report, as an additional year's worth of data (with a corresponding increase in the number of schools, grades, and students covered) is added to the study.

We show a variety of specification tests to assess the robustness of our empirical strategy. We explore a number of other topics such as whether achievement effects vary with a student's grade at testtaking, whether achievement effects vary with the grade at which the student entered the charter school, and so on. In no case are we able to discern interesting patterns, possibly because the data are still insufficient to support fine cuts of the results but probably because students at a given charter school (regardless of grade and entry) have more in common than students in a given grade across all charter schools.

\section{Some Background on Charter Schools in New York City}

A charter school is a public school that operates fairly autonomously within guidelines laid down by its state. Charter schools are generally free to manage day-to-day operations, hire teachers and let them go, choose salary schedules, and make curricular decisions. Charter schools must advertise their availability to all students who are eligible to attend the public schools, and they are not allowed to select 
students. Specifically, if a charter school in New York receives more applicants than it has places, it must hold a random lottery among the applicants. Lotteries are specific to a school, grade, and year of intended entry--for instance, the lottery for the fourth grade class commencing in fall 2005 in charter school X.

When a charter school enrolls a student, the student essentially brings a "fee" with him that is taxfinanced. In New York State, a formula determines this fee and it is usually between two-thirds and fourfifths of what would be spent on the student's education if he remained in the traditional public schools. ${ }^{2}$ Charter schools that are moving into or renovating facilities may also get some funding from the state's Stimulus Fund. However, the key thing to remember about charter schools is that they cannot survive if they cannot attract students because they will simply not have the necessary funds. Thus, families automatically exercise some governance over charter schools when they "vote with their feet" by choosing whether to apply or whether to keep their child enrolled. In addition to this governance exercised by parents, charter schools must get initial approval for their start-up from an authorizer, who examines proposals and accepts some and rejects others on the basis of educational and fiscal soundness. Every few years (five in New York), a charter school must have its charter renewed by this same authorizer. Charter renewal is typically a period of scrutiny for the school. Between renewals, a charter school's leaders must answer to their board, which is typically composed of local leaders, people from community organizations, and other educators. Finally, charter schools--being public schools--participate fully in their state's and the federal government's accountability system. For instance, their student take all statewide tests.

In New York State, charter schools are authorized by the Charter Schools Act of $1998 .^{3}$ In the first year of operation for charter schools, 2000-01, ten schools began operating. Four of the schools (Wildcat Academy, Renaissance, KIPP Academy, and Beginning with Children) were conversions of previously-existing public schools that had had unusual programs and autonomy. ${ }^{4}$ Subsequently, five schools opened in 2001, two schools opened in 2002, five schools opened in 2003, nine schools opened in 2004, and eleven schools opened in 2005 (including one conversion school, Future Leaders Institute).

This article is the first research-oriented report from a multi-year study in which we hope to

2 See Center for Education Reform (2007).

3 The New York State Charter Schools Act of 1998 (as amended) is Article 56, Sections 2850 to 2857 of the New York State Consolidated Laws.

${ }^{4}$ They were part of the "New Visions" initiative started by New York City Schools Chancellor Rudy Crewe (X). When they converted, they brought with populations of students who applied and who were admitted partly on the basis of a lottery and partly on the basis of priorities decided by the 
engage all New York City charter schools with an exception described below. When we refer to this "article" or "report," we mean this document. When we refer to the "study," we mean the ongoing study. Because there are new schools opening each year in New York, some schools that currently exist are not covered by this article even though they are participating in the study. The 2005-06 school year is the most recent period for which we have achievement data for this report.

\section{A. Participation by New York City Charter Schools in this Study}

There were 47 charter schools operating in New York City as of the 2005-06, and all but a few are participating in the study. Two schools, Manhattan Charter School and South Bronx Charter School for International Cultures and the Arts, are not included in this report but are participating in the study. Because the two schools do not yet have any students in test-taking grades, their not being included in this report has no effect on the achievement results. One school, Readnet Bronx Charter School, was in the process of closing in 2005-06. We will include this school in future reports if we are able to retrieve information retrospectively about applicants to the school's lotteries. The omission of Readnet Bronx is likely to have only small effects because the school had only two years of test-taking students: third and fourth graders in 2005-06 and third graders in 2004-05. The NY Center for Autism Charter School is not included in the study because it serves a very special population and is not compatible with many elements of the study. The United Federation of Teachers Elementary Charter School has declined to participate in the study thus far. Because it does not yet any students in test-taking grades, its not being included in this report has no effect on the achievement results.

All of the other charter schools in New York City are covered by this year's report. For the number of students from each application year who are included in the study, see Table 5, which is discussed below.

Aggregate results reported in this report, for instance the average effect of charter schools on math scores, reflect the student's experience. Thus charter schools that enroll more students generally have more effect on the overall results. Given the principles on which charter schools are based, this student-weighted approach is the right one. If successful charter schools expand and unsuccessful ones shrink, we should not attempt un-do these dynamics with statistics. The expansion and shrinkage is part of the charter school policy, which is intended to create an average student experience in which unsuccessful schools are forced to play a small role and successful schools are allowed to play a big role.

\section{B. Grades Served by New York City Charter Schools}

Of the 42 charter schools covered by this article, four plan eventually to serve all of grades kindergarten through twelve. 26 schools plan to focus on elementary grades. (One school plans to serve grades kindergarten through four, twelve schools plan to serve grades kindergarten through five, four 
schools plan to serve grades kindergarten through six, ten schools plan to serve grades kindergarten through eight, and one school plans to serve grades one through eight.) The remaining schools plan to focus on traditional middle-school grades or a combination of middle and high school grades. (Four schools plan eventually to serve grades five through eight, four plan to serve grades five through twelve, one plans to serve grades six through twelve, one plans to serve grades eight through twelve, and one plans to serve grades nine through twelve.) Table 1 shows the number of schools operating during each recent school year and the grades being served that year.

Often, charter schools in New York City open with only their lowest grade, the "intake" grade, and add a grade each subsequent year. This is known as "rolling up." For example, a charter high school may open with only ninth grade. By rolling up, the school serves all of the high school grades from nine to twelve by its fourth year of operation. Because kindergarten and first grade are both traditional intake grades, charter elementary schools in New York City often open with both kindergarten and first grade. By their fifth year of operation, they have rolled up to serving kindergarten through grade five. Rolling is supposed to give schools a manageable way to grow and to instill their school's culture and standards into students.

Charter schools do not always roll up. Some open by admitting students into intake and nonintake grades alike. Schools that convert to charter school status in New York City typically do so with their full complement of grades. As a rule, however, once a school gets past its first year or two of operation, its admissions are dominated by its intake grades. Non-intake grades admit only a trickle of students to fill places that happen to open up when students depart. Thus, a charter elementary school might run a kindergarten lottery to fill 50 places, a first grade lottery to fill 25 places, and second through fifth grade lotteries to fill a couple of places in each of those grades. ${ }^{5}$

Table 2 shows how applicants to New York City charter schools by the grade to which they applied. The intake grades of kindergarten, one, five, and nine stand out. Almost one third of applicants applied to kindergarten, and just under one half of all applicants applied to kindergarten or grade one. 14

${ }^{5}$ Owing to the peculiarities of New York City school facilities and the large number of special schools within the traditional public system, some charter schools have intake grades that would not be obvious based on the range of grades they serve. For instance, one might expect that Renaissance Charter School, which serves kindergarten through grade twelve, would do nearly all of its intake in kindergarten and grade one. In fact, the facilities it was granted allow it to serve only one class per grade through fourth grade and two classes per grade thereafter. Also, its students are fairly successful in gaining admissions to the International Baccalaureate school which begins with the seventh grade and some of the more sought-after high schools, such as the exam schools, which begin with the ninth grade. In short, the school has several intake or partial intake grades: kindergarten, first, fifth, seventh, and ninth. 
percent of applicants applied to grade five and 2.5 percent applied to grade nine. Apart from these intake grades, the percentage of applicants declines monotonically with the grade level. Table 2 actually understates the degree to which the intake grades dominate current and will dominate future admissions. This is because the table includes years in which numerous charter schools in New York opened (see Table 1), and we have pointed out that start-up schools sometimes admit whole cohorts of students into non-intake grades.

C. The Neighborhoods where Charter Schools are Located within New York City

In 2005-06, charter schools were located in all of the boroughs of New York City except for Staten Island. See Figure 1, which maps the schools' locations. Notice the clusters of charter schools in Harlem (Manhattan) and in the South Bronx.

When a charter school, especially one that serves elementary grades, locates in a neighborhood, it can expect to serve students who are disproportionately from that neighborhood. Thus, it is useful to know how the charter schools' neighborhoods compare to the rest of New York City. Table 3 shows census data for the average tract in which a charter school is located and for all the tracts in New York City. Charter schools locate in neighborhoods that have unusually low proportions of white and Asian residents and unusually high proportions of black and Hispanic residents. Families in charter schools' census tracts have disproportionately low median incomes and are disproportionately likely to be below the poverty line. The adults in these tracts have disproportionately low educational attainment, and the children are disproportionately likely to be living with a single parent. 62 percent of the charter schools are located in a tract where, relative to the New York City averages, a high percentage of families live in poverty (greater than 21.2 percent), a low percentage of adults have bachelor degrees (lower than 27.4 percent), and a high percentage of children live with single parents (greater than 28.8 percent). Another 17 percent of the charter schools are located in neighborhoods that satisfy two of the three above criteria. The only charter school located in an affluent tract, Wildcat Academy, is exclusively for likely high school drop-outs. Its location is sensible not because its students reside near the school but because they do internships with firms as part of their education. Many firms are located close to the school.

\section{The Authorizers and Operating Agencies of New York City's Charter Schools}

There are three agencies with the power to authorize charter schools in New York City: the trustees of the State University of New York, the Chancellor of the New York City Schools, and the New York State Board of Regents. When a group of individuals decides to form a charter school, they write a proposal. They may submit this proposal to only one authorizer at a time. As of the 2005-06 school year, the trustees of the State University of New York had authorized 20 of the charter schools covered by this report and the Chancellor had authorized 19. The Board of Regents had authorized only three schools in 
New York City but had authorized many charter schools in the state, outside of the city. See Figure 2.

Each charter school has an operating agency. If, as is typical, the operating agency helped to write the charter school proposal, it is also called the founding agency. There are three types of operating agencies in New York City: non-profit Community Grown Organizations (CGOs), non-profit Charter Management Organizations (CMOs), and for-profit Education Management Organizations (EMOs). CMOs and EMOs are formal organizations that exist to manage charter schools, and they function somewhat like firms that have a strong brand and that establish fairly independent branches or franchises. CMOs and EMOs typically make overarching curricular and policy decisions, conduct back office activities, and provide something of a career ladder for teachers and administrators within their network of schools. The CMO with the most schools in New York City as 2005-06 is the KIPP Foundation, and the EMO with the most schools is Victory Schools

The CGO category is something of a catch-all and, thus, CGO schools are much more varied. They may be founded by a group of parents, a group of teachers, a community organization that provides local social services, one or more philanthropists, or the teachers union. More often than not, the founding group combines people from a few of the groups listed above. We classify the conversion charter schools as CGOs because they were started by groups like those listed above. Figure 3 shows that 56 percent of the charter school students covered by this report attend 23 schools whose agencies are CGOs, 19 percent attend 12 schools whose agencies are CMOs, and 25 percent attend 7 schools whose agencies are EMOs. Notice that the average school with an EMO has considerably larger enrollment (3.6 percent of enrollment per school) than the average school with a CGO (2.4 percent of enrollment per school) or a CMO (1.6 percent of enrollment per school).

\section{E. The Missions and Characteristics of New York City Charter Schools}

Each charter school describes itself in a carefully crafted mission statement that sets out its vision, educational philosophy, and focus. The statements are prominent on the schools' materials for prospective parents, student, and staff, so it is fair to assume that they reflect a school's tendencies (if not ex ante, then ex post as they attract people to whom the statement appeals). While we cannot reduce mission statements to simple variables, we can categorize them roughly into five groups: those with a child-centered or progressive educational philosophy (29 percent of students); those with a general or traditional educational mission ( 28 percent of students); those with a rigorous academic focus ( 25 percent of students); those that target a particular population of students (11 percent of students); and those in which a certain aspect of the curriculum is paramount ( 7 percent of students). Figure 4 shows the proportions of students and schools in each category.

There is a good deal of overlap in schools' missions, but a few key features allowed us to put 
them into categories. Child-centered or progressive schools typically seek to develop students' love of learning, respect for others, and creativity. Such schools' mission statements may also focus on helping students realize their potential and on building strong connections between students and their families and communities. Schools with a general or traditional educational mission typically seek to develop students' core skills and would like to see them meet or exceed New York State's academic standards. Schools with a rigorous academic focus have mission statements that almost exclusively mention academic goals such as excelling in school and going to college. These schools also frequently state that they would like their students to become leaders. Schools with a mission to serve a targeted population of students include those that focus on low-income students, special needs students, likely drop-outs, male students, and female students. The remaining schools use a special focus, such as science or the arts, to structure their whole curriculum.

There are many reasons to expect that charter schools will choose different policies and practices. They are independent and fairly autonomous. Their operating agencies have a variety of histories and priorities. All are young schools and more likely to experiment with new policies than are established schools. At the same time, there are reasons to think that New York City's charter schools will share certain policies. They commonly serve disadvantaged students; they are all under pressure to attract parents and to satisfy a small number of authorizers; they may imitate one another consciously by deliberating adopting another school's policy that seems to be working; they may also imitate one another unconsciously (as when teachers who have worked at one school are hired by another and bring their knowledge with them).

Table 4, which shows the share of the charter schools with each of a number of characteristics, demonstrates that the schools vary a lot but that there are also distinguishable patterns among them. Knowing the schools' characteristics is useful for two reasons. First, one can learn which policy innovations seem promising to the leaders of urban schools who have the power to select their policies. Second, different charter schools have different effects on achievement. Later in this article, we attempt to see which characteristics are associated with more positive effects on achievement.

About 91 percent of charter school students attend schools that require uniforms, about 95 percent attend schools that voluntarily administer standardized exams on a regular basis for diagnosis purposes. Exams such Terra Nova, the Iowa Test of Basic Skills, and the Stanford 9 are administered to track progress and identify students in need of different instruction. (All charter schools also administer the standardized exams required by the state of New York.) The advisory system is used by nearly all the charter schools that serve middle or high school grades. In an advisory system, a teacher or pair of teachers is assigned to a group of students for an entire school year. Teachers meet frequently (often 
daily) with their students and are responsible for tracking their progress and preventing them from "falling through the cracks." Because students in elementary grades are assigned to one teacher for most of the school day, advisory systems would be duplicative and are therefore not used by elementary schools.

About 64 percent of students attend a charter school with a school year of 190 days or longer, and 20 percent attend a school with a school year of 200 days or longer. The modal school year in the United States is 180 days or 36 weeks. About 55 percent of students attend a charter school with a day that last eight hours or longer, 67 percent attend one with an optional after-school program, and about 57 percent attend one with Saturday school that is mandatory for all or at least some students (for instance, students who are struggling academically). 54 percent of students have an extended English or Language Arts period of over 90 minutes, and the same percentage have an extended math period of 90 minutes or more. While 90 minutes is the length of the "literacy block" mandated for elementary school grades by the Children First initiative in New York City, traditional public elementary schools in New York City are required to have between 60 and 75 minutes of math instruction daily, depending on the grade.

About 52 percent of students attend charter schools that ask their parents to sign "contracts." Because the contracts are not enforceable as contracts, it is best to think of them as method of trying to ensure that parents know about the school's policies and expectations. Some parents may also feel morally bound to abide by the contract. 52 percent of students attend a charter school that reserves one or more seats on its board for parents. About 21 percent attend one with a disciplinary policy that fits the "No Broken Windows" school of thinking which holds that small courtesies and punishing small infractions (usually at classroom level) are important. This is in contrast to disciplinary strategies that focus more on preventing or punishing large infractions (often at an administrative level above the classroom $)^{6}$

The charter schools employ a variety of math and reading curriculum with no dominant curriculum. The most popular are Saxon Math (41 percent of students) and Core Knowledge (38 percent of students.) See the appendix for descriptions of some of the curricula used by multiple charter schools.

About 49 percent of students attend a charter school that has a system of bonuses for successful teachers. Finally, 17 percent of students attend a charter school whose teachers are unionized. Unfortunately, the variation in unionization is not as useful as one might think. The problem is that the

${ }^{6}$ We did not require that a school use terminology like "No Broken Windows" to classify it as having this disciplinary strategy, but we may nonetheless have understated the share of schools that have the strategy. This is because disciplinary strategies are often described in terms that are too vague to allow. 
five conversion schools dominate the unionized group, and this makes it hard to tell unionization apart from conversion, which comes with a variety of other special circumstances. ${ }^{7}$ In future reports, we plan to include teacher certification and experience data that are not available on consistent basis for this year's report.

\section{Data}

Most of the data used in the study are derived from the administrative database of New York City's Department of Education (the "New York City Basic Educational Data System"). This database includes all students who attend New York City's traditional public schools and all students who attend New York City's charter schools.

The procedure for our data assembly is as follows. Each spring, charter schools review the applications (typically a single page with fill-ins) they have received, put the applications into lotteries if the school is oversubscribed, and hold their admissions lotteries. We ensure that the data from each student's application is sent to the New York City Department of Education. A typical applicant's data would include his name, birth date, parents' or guardians' names, address, telephone number, and the grade to which he is applying (usually, but not always, the grade he is attending plus one). Additional data that are sent if available include the student's current school, his social security number, and his identification number in the New York City Department of Education (the "OSIS number"). Of course, some students' applications are incomplete or hard to decipher, and the student's data are then missing one or more elements, such as a telephone number. The data are matched to the Department's database by a contractor for the department using the maximum amount of information possible. ${ }^{8}$ Application data that

${ }^{7}$ For instance, the conversion charter schools have all operating longer--in some cases, much longer--than the other charter schools. Some conversion charter schools still have students enrolled who applied (or whose siblings applied, giving them priority) in the days before they used only lotteries for admission. See footnote $4(\mathrm{X})$.

8 For students who did not match on the basis of a unique identification number, such as a Social Security or OSIS number, match keys were used as follows: (i) last name, first name, date of birth with various versions of the names (abbreviations, alternative spellings, and so on); (ii) last name, first name, and various likely permutations of the date of birth (most often the month and day reversed since Americans are fairly unique in putting the month before the day); (iii) last name, first name, prior school, and prior grade with various likely adjustments to prior grade; (iv) name, date of birth, and prior grade; (v) telephone number and alternative telephone number. Once these match keys had been run, an applicant might be matched to multiple possible records. All of the likely matches were checked by hand, bringing to bear all available variables simultaneously. Knowledge of common abbreviations, spelling mistakes, and similar issues was also applied in the hand check. For instance, two possible matches might be differentiated based on the student's home address or his parents' names. 
matched to more than one possible record in the database were checked by hand to determine which of the possible matches was correct. Once an applicant had been matched to his record in the database, information was extracted on his characteristics; enrollment; attendance; test scores, and certification for and participation in various programs such as free and reduced-price lunch, special education, and English language services. This information was gathered both from the years prior to his applying to a charter school and from the years after his applying. We were able to obtain test score data from 2000-01 to 2005-06 for this year's report. When the information had been gathered, it was sent to us with a masked or encrypted student identification number.

\section{A. Match Rates}

When this study commenced, we advised schools on the variables that we would like to see on their applications because they would be useful for matching. We obtained application data from spring 2005 from all of the schools covered by this year's report, and we requested earlier years' application data as well. Because schools had not been aware that these earlier years' application data would later be useful, not all schools had archived it or had requested all of the elements that would prove helpful in matching on their applications. Therefore, the 2005-06 application data have the most complete coverage of schools and the most information on which to match. Previous years' application data are less ideal on both dimensions. Going forward with applications in spring 2006, spring 2007, and so on, we have already obtained or expect application data at least as good as the 2005-06 data.

We should not achieve a match rate of 100 percent because applicants who were not attending a New York City public school at the time they applied and who did not subsequently attend one should not have matched to a record in the database. Such applicants include children applying for kindergarten who subsequently attend a private school, enroll in a public school outside the district, or engage in home schooling. Such applicants also include children who were attending a private school, another district's schools, or home schooling when they applied and who continued to attend such a school. Note that students can apply to a New York City charter school from outside the district so long as they reside in the district at the time they actually commence attending the school. To determine what match rate we ought to achieve, we computed the percentages of applicants who reported, at the time they applied, attending a private school (14 percent), engaging in home school (less than 1 percent), and living in another district (less than 1 percent). Unfortunately, the first computation does not help with students who are applying to kindergarten, the single most common grade for applicants. Moreover, there are a large number of private kindergartens in New York that are not connected to a full array of elementary 
grades, and we are concerned that students who apply to a first grade from a private kindergarten might not be able to continue in private school. Thus, we also use the Integrated Public Use Microdata Samples from the 2000 Census to compute the percentage of New York City students who attend private school: 10.6 percent. To make this computation, we re-weighted the students in the Census data so that they had the gender, race, ethnicity, and poverty composition of the applicant pool. ${ }^{9}$

In short, although we hope to match all applicants who have a record in the Department's database to their records, we believe that we should be able to match only about 90 percent of students, plus or minus a few percent. There is some variation among charter schools in their ideal match rates because some schools attract more applicants from private schools and so on.

The match rate for spring 2005 applications was 90.8 percent. Recall that this is the year for which we had the highest quality application data. The match rates for spring 2004 and spring 2003 were 88.4 and 88.7 percent, respectively. The match rate falls to about 81 for spring 2002 and 2001 applications, but is 88 percent for spring 2000 applications. The relatively high match rate for spring 2000 , despite its being an early year, is related to the fact that many of that year's applications were made to conversion schools which had full access to the database when they were processing and/or archiving application data. For full details on the match rate, see Table 5, which also shows that an extremely high percentage of students who have ever attended a New York City charter school are included in the study. Over all the years available, the percentage is 97 percent. ${ }^{10}$

B. Substantial Problems in the Recording of Special Education and English Language Learner Status and Minor Problems in the Recording of Other Classification Variables

There are problems in the recording of special education and English Language Learner status in the database we use in this report. The problems can lead to very substantial underestimates of disability and the need for English language learning in charter schools.

Consider special education first. According to our understanding, which is based on communications with the New York City Department of Education and the New York City Center for

9 Specifically, using the combined 5 percent and 1 percent samples from the 2000 Integrated Public Use Microdata (Ruggles, 2007), we computed the probability of attending a private school for each gender-by-race or ethnicity-by-free or reduced-price lunch cell. We then associated those probabilities with each applicant based on the applicant's cell. The resulting average probability among the applicants is what we provide in the text.

${ }^{10}$ See notes to the table for further detail. 
Charter School Excellence, there are three main problems that occur. ${ }^{11}$ A school that refers a student for special education must work with the Committee on Special Education to get him formally identified, and some charter schools have experienced significant delays getting this done. The charter schools have little control over the timing because the Committee on Special Education is the responsibility of the host district--in this case, New York City. Students can sit in the referral queue for extended periods, and so long as they are there, they are not recorded as having special needs. Second, even when a student has been formally identified, a subsystem of the New York City database known as CAPS must be updated to reflect the student's designation. Traditional public schools have direct access to CAPS, but most charter schools can get entries updated only by working through the Committee on Special Education or through a third party contractor. Not only can there be delays and problems in the updating of a student's designation, but the system must also be updated to show that a student has moved into a charter school. Apparently, this second update is sometimes overlooked, with the result that student's special education status is not attributed to the charter school. Third, although there is a "flag" for special education in the main part of the database system known as ATS, charter schools are only required to maintain students' enrollment and other basic information in ATS. This is because many charter schools use another student information system as their primary system. In contrast, ATS is the primary student information for traditional public schools, which are required to maintain not only their basic information but also flags like the special education flag. When a charter school leaves the special education flag blank, the system appears to produce the answer that no students are in special education when, in reality, the system simply contains no information on the question. In other words, missing data are not differentiable from "zeros" (students' non-participation in special education).

In short, there are three important problems with the recording of charter school students' need for special education, and all three problems cause under-reporting. When we compare the percentage of special education students in charter schools that we compute from the data extracted for us from the database to the offical state count ( 8.90 percent $)$, the official count is more than three times our count. This is a such a large discrepancy that, at present, we cannot use the database numbers to make comparisons between students in charter schools and students in traditional public schools. However, we do show statistics based on the pre-lottery designations of students who apply to charter schools while

11 For help in understanding these problems, we are particularly grateful to Jennifer BellEllwanger, Senior Instructional Manager, Office of Assessment and Accountability, New York City Department of Education and to Arthur Sadoff, Special Education Consultant to the New York City Center on Charter School Excellence. 
they are in the traditional public schools. As we shall see, pre-lottery designations have their own problems but they are much less severe because all of the recording is done through the traditional public school system.

The recording of a student's status as an English Language Learner status is also problematic for charter schools. There is a "flag" for English Language Learners in the ATS part of the database system, but--like the flag for special education--charter schools are not required to maintain it and may leave it blank for all students. The system then appears to produce the answer that no students are English Language Learners when, in reality, the system simply contains no information on the question. This problem may be exacerbated by the fact that charter schools receive only a fraction of the compensation for English Language Learners that traditional public schools receive. This gives them little incentive to fill in the flag. When we compare the percentage of English Language Learners in charter schools recorded in the database to the offical state count ( 2.80 percent), the official count is more than twice the database count. This also is such a large discrepancy that the database numbers cannot be used to make comparisons between students in charter schools and students in traditional public schools. We do show statistics based on pre-lottery designations, but these have their own problems (see below).

Some of the same problems (recording delays, ATS flags not filled in) exist for the recording of students who have been certified for the National School Lunch Program. Charter schools' numbers are understated as a result, especially for new entrants. We estimate the magnitude of the understatement to be about 8 percentage points. Finally, charter schools report that they find it hard to correct the database when it shows a student's race and ethnicity as being different than what the school knows the student's self-identification to be. ${ }^{12}$ The latter problem appears mainly to affect students whose parents check multiple boxes for race and ethnicity. ${ }^{13}$

\section{New York State Tests}

All students in the traditional public schools and charter schools take the New York State examinations in reading and math in all of grades three through eight. They also take (and may retake)

12 The source is authors' conversations with charter school leaders regarding differences between race and ethnicity as parents wrote it on applications and race and ethnicity as shown in the Department's database.

13 The rule for the standard federal classification is that Hispanic ethnicity "trumps" race so that the categories are black non-Hispanic, white non-Hispanic, Asian and Pacific Islander, Native American, Hispanic, and unknown or none of the above. School staff report, however, that it appears to them that the rule is not always applied so that a parent, say, who checks the black and Hispanic boxes may have his child classified as black. 
the New York State Regents Examinations in several subjects. The Regents Examinations are offered in January, June and August, and a student need not take tests on a specific schedule. However, to earn a high school diploma, a student must pass exams in Living Environment (biology), Mathematics, Global History, Comprehensive English, and U.S. History. It is recommended that students take Living Environment in grade nine, Math A in grade ten, Global History in grade ten, Comprehensive English in grade eleven, and United States History in grade eleven. Scores from all New York State tests are sent to the New York City Department of Education and transferred into its database. It is our understanding that there are no differences, therefore, in how scores get recorded for charter and traditional public school students.

The tests for grades three through eight are given scale scores and there is an official mapping between the scale scores and New York State's four performance levels. See Appendix Figures 1 and 2 for the 2005-06 mapping for math and reading. Throughout our analysis, we use standard or Z scores-that is, scale scores that have been first demeaned and then divided by the standard deviation. We use the means and standard deviations for all New York City students in the relevant year and subject. Purely to provide context, we translate a few effects based on standard scores back into scale scores or "performance levels." When we do this, we use the 2005-06 translations. A great deal of information about New York State's tests is available from the Office of State Assessment. ${ }^{14}$ D. Differences between the Truth and Proxies for Poverty, Disability, and the Lack of proficiency in $\underline{\text { English }}$

Researchers who rely on administrative data, as we do, do not directly measure poverty, disability, or the lack of proficiency in English. Instead, we use proxies such as certification for the National School Lunch Program, participation in special education, and classification as an English Language Learner. Here a problem arises (in addition to the already described recording problems) because the proxies are measures of treatment, not measures of a child's needs. If we use data on these proxies from a student's current school, the comparison between charter school applicants and other public school students is unreliable. The unreliability stems from differences in the ways charter schools and traditional public schools certify students for free and reduced-price lunch and treat students who have learning problems or a lack of proficiency in English.

For example, consider free and reduced-price lunch eligibility. In order to certify a child for the

14 The website of the Office of State Assessment in the New York State Education Department includes examination scoring information, score conversion charts, manuals and technical reports on the tests, test samplers, and tests that have been released. See http://www.emsc.nysed.gov/osa/ (accessed June 2007). 
program, a school must get his parents to must document their household's income and composition (adults, dependent children, other dependents, and so on). Certifying parents is a sufficiently challenging task that federal studies regularly find that some schools certify students who are not really eligible and that other schools fail to certify students who are really eligible. ${ }^{15}$ Schools vary in how they describe program eligibility and documentation requirements, whether they use direct certification, and whether they encourage parents whose applications are rejected or whose certification is terminated to reapply. ${ }^{16}$ The matter is complicated by the fact that schools can provide a schoolwide lunch program if they certify a sufficient share of their students. Thus, the same administrator who is aggressive about certifying students when he is at a school that is just shy of the threshold for a schoolwide program may be unaggressive when he is at a school that has already passed the threshold. Charter schools are, for the purpose of federal programs, independent Local Education Agencies that conduct their own processes of certifying students and may choose not to offer a federal lunch program at all. Numerous small school districts in the United States do not participate in the federal program owing to the fact that the paperwork involved is considerable but the subsidy is small for small districts because it is on a strictly per-pupil basis.

Problems arise with special education and English Language Learner classification because for every student who is profoundly disabled or profoundly incapable in English, there are many students whose classification is close to the margin in the sense that, properly implemented, either a mainstream or a specialized experience could suit the student's needs well. A small school, including a charter school, may be more likely to offer a marginal student a student a mainstream classroom experience--thereby not classifying him--than would a large school that already has extensive programming for disabled and English Language Learner students. In fact, Cullen and Rivkin (2003) report that some families apply to charter schools in a deliberate attempt to change the status of their marginally classified child.

In short, we expect charter schools and traditional public schools faced with identical students to display variation in the proxies for poverty, disability, and the lack of proficiency in English. We can partially address the resulting problem (and the already described recording problem) by focusing on the value of a student's proxies at the time he applied rather than at the current time. For students who were (2003).

${ }^{15}$ See, for instance, Burghardt and Hulsey (2004) and United States Department of Agriculture

${ }^{16}$ Most large school districts currently use direct certification for students whose parents claim to be participants in a means-tested program such as Temporary Aid for Needy Families. Such parents are asked to bring recent documents relating to their program participation and these are checked against state social insurance records. 
in the traditional public schools at the time they applied, this procedure improves the reliability of comparisons owing to the fact that the same Local Education Agency is classifying all the students. In particular, this procedure should greatly improve the reliability of a comparison between two applicants who are in the same lottery and who previously attended similar traditional public schools. Unfortunately, time-of-application comparisons are not informative for more than 50 percent of charter school applicants because they have no classification history when they apply. The vast majority of the students without a history are applicants to kindergarten or first grade (who together make up almost 50 percent of all applicants; see Table 2) but there are also applicants from private schools, home schooling, and schools outside the district.

E. Attrition

A student attrits from the study if his family moves out of the district, he begins attending private school, or he begins home schooling. Because of errors in the database, a student might also attrit in practical terms when he does not actually leave the public school sector in New York City. This can happen if he moves to a new school within the district and his information is entered differently so that his old and new records do not match up. A student is not counted as an attritor if he graduates from high school.

Apart from considerations of power, attrition is not a problem for studies of this kind if it is random. Attrition is a problem when it is substantial, systematically related to students' characteristics, and systematically related to whether a student is lotteried-in or lotteried-out. For instance, if low achieving applicants and high achieving lotteried-in applicants stayed in the data but high achieving lotteried-out applicants attrited with a 10 percent probability, the lotteried-out group would systematically lose a portion of its high achievers while lotteried-in group would keep its high achievers.

Fortunately, the attrition rates in this study are so far extremely low. Among all applicants, only 0.12 percent of those who have enrolled in charter schools have attrited, and the attrition rate is just 0.02 percent lower for applicants who have not enrolled. Only 0.15 percent of those who were lotteried-in have attrited, and the rate is only 0.11 percent lower for the lotteried-out. See Table 6, which also shows that there are not statistically significant differences at the 95 percent level between enrolled and not enrolled or between lotteried-in and lotteried-out in any subgroup of applicants: female, black, Hispanic, white, Asian, other race, certified for free or reduced price lunch, participants in special education, English Language Learners. All of these subgroups have attrition rates below 1 percent.

We believe that the very low attrition rates are due, in part, to the fact that New York City is a massive district and that the charter school applicants tend to be disadvantaged. A student can move quite far among the five boroughs and remain in the district. Applicants are unlikely to move to the suburbs 
outside the City because housing in the suburbs is mostly outside their families' price range. Moreover, the study is still young. In many cases, we are using data on a student from just one, two, or three years after he has applied. Even if he is going to attrit eventually, he might very well not have attrited yet. We show a specification test for the effects of attrition below, and we will monitor attrition closely in future reports.

\section{$\underline{\text { F. Miscellaneous Data Issues }}$}

We observe students' October, March, and June records, the last being the official year end record. Thus, a student who transfers in the middle of the school year between schools will have each school assigned its portion of the year, at least approximately. ${ }^{17}$ Also, variables such as the time elapsed since a student starting attended a charter school are recorded in partial years when appropriate.

Finally, to provide background information, we use data from published reports of the New York City Department of Education (various dates), published Summary File C of the 2000 Census of Population and Housing (2002), and the Integrated Public Use Microdata Samples from the same Census (Ruggles, 2007).

\section{The Students who Apply to New York City's Charter Schools}

In this section, we would like to be able to compare the charter schools' applicants to public school students, both in New York City overall and in the specific traditional public schools from which the charter schools draw students. Unfortunately, it turns that most such comparisons cannot be made in a way that is reliable or easily interpretable. Only comparisons based on characteristics of students that are fixed over time and easily measurable turn out to reliable.

\section{A. Comparisons of applicants to others on the basis of gender, race and ethnicity}

The characteristics that are most fixed and most easily measurable are gender, race, and ethnicity. We have already mentioned that there are may be some problems with race and ethnicity because charter schools do not directly enter their data into the database and are concerned that mixed-race or mixed ethnicity children sometimes get recorded incorrectly. Subject to this caveat, Table 7 shows gender, race, and ethnicity variables for charter school applicants, a composite comparison school, and all traditional New York City public school students. The composite comparison school is a weighted average of the

${ }^{17} \mathrm{We}$ are attempting to get even more complete attendance records that will allow us to allocate partial years more precisely, but specification tests suggest that varying our approximations a reasonable amount does not make a difference to any results. The vast majority of students switch schools between school years. 
characteristics of all of the traditional public schools from which the charter schools draw applicants. For instance, if the fourth grade cohorts in traditional public schools A and B account for, respectively, 0.3 percent and 0.2 percent of the applicants, the gender ratios of these cohorts will get weights of 0.03 and 0.02 when we create the composite comparison school's gender ratio. (A cohort is all students who attend a certain grade in a certain school in a certain year.)

Table 7 shows that about 48 percent of charter school applicants are female, about 50 percent of students in composite comparison schools are female, and about 49 percent of all New York City traditional public school students are female. The differences between these percentages are too small to be interesting even though they statistically significant, owing to the large number of applicant observations. ${ }^{18}$

Table 7 also shows that, on the basis of being white non-Hispanic, Asian, and other race or ethnicity, charter school applicants appear very similar to students in the composite comparison schools. The differences, though statistically significance in some cases, are too small to be interesting--especially in light of the data recording issues already mentioned. For instance, about 3.3 percent of 2005-06 applicants and about 2.3 percent of composite comparison school students are Asian. However, neither the applicants nor the composite comparison school are similar to New York City's population of public school students, 14 of whom are white and 14 percent of whom are Asian.

The composite comparison school (for the 2005-06 applicants) is about 50 percent black and about 45 percent Hispanic. This makes it both more black and more Hispanic than New York City's population of public school students ( 32 black and 39 percent Hispanic). This also makes it clear that the charter schools draw from a population where the vast majority of students (95 percent) are either black or Hispanic. In consequence, if a school disproportionately attracts black applicants, it will almost mechanically disproportionately not attract Hispanic students, and vice versa. People often find this mechanical relationship confusing because they are accustomed to thinking about a school being more minority and less white. The bottom line is that when we say that a charter school is more black, we are also saying that it is less Hispanic, and these are not two separate findings but two ways of stating the same finding.

Table 7 shows that 64 percent of charter school applicants are black. Compare this to the 50 percent of composite comparison school students and 32 percent of New York City public school students who are black. There is an approximately equal and opposite disproportionality for Hispanic students: 27

${ }_{18}$ See notes to the table for details on how we treat the composite comparison school's numbers for the purpose of testing for statistical significance. 
percent of applicants are Hispanic but composite comparison schools are 45 percent Hispanic. One explanation of the disproportionate draw of charter schools among black students is that the authorizers have approved some schools that are named after a black person (Harriet Tubman, Sisulu Walker) or associated with a community organization with long-established ties to the black community (Harlem Children's Zone). However, the disproportionate draw is much wider than these schools, suggesting that policies that are common among charter schools but uncommon among traditional public schools may appeal more to black families (less to Hispanic families). Alternatively, Hispanic families may simply like their children's traditional public schools better or be more inclined to accept their traditional public school as the one that authorities have assigned them. ${ }^{19}$

B. Comparisons of applicants to others on the basis of proxies for poverty, disability, and lack of proficiency in English

We have already mentioned that the proxies for poverty, disability, and lack of proficiency in English are problematic because (i) they are measures of treatment, not circumstances, and charter and traditional public schools may treat marginal students differently; (ii) charter schools' information is recorded with substantial understatement; and (iii) the proxies are available at the time of application for only a share of applicants.

Unfortunately, the applicants for whom time-of-application proxies are available are not representative of the applicant pool. This is shown in the top panel of Table 8 where a comparison is made between the intended grade of entry, gender, race, and ethnicity information of applicants who do and do not have time-of-application proxies available. Intended grade, gender, and so on have limited value as indicators of whether the two groups are similar on poverty, disability, and proficiency in English, but they are the only indicators available. Nevertheless, each of the indicators is statistically significantly different for the two groups and some of group differences are substantial in magnitude: the average grade of intended entry is 3.7 for students with time-of-application proxies but only 1.9 for students without them. About 32 percent of students with time-of-application proxies are Hispanic but only 23 percent of students without them are.

${ }^{19}$ In both the New York City traditional public schools and in charter schools located in areas with a significant Hispanic population, key materials (such as applications, school calendars, and brief school descriptions) are usually available in Spanish but many non-key materials (such as school newsletters and longer program descriptions) are not. We are thus inclined not to attribute the disproportionate draw of charter schools to language proficiency alone but to an interaction between language proficiency and an inclination to accept the default. That is, if a parent finds it equally challenging to learn in depth about his local traditional public school and his local charter school, he may be inclined to choose the default school. 
Unfortunately, there is a further problem. When we come to construct the composite comparison school, we cannot do so in as exact a way as we did for gender, race, and ethnicity. The reason is that the proxies are available only at the school level, not the school-by-grade level, for traditional public schools. As a result, the applicants and the composite comparison school have different grade compositions in Table 8. Since students take time to get classified, differences in grade compositions cause incomparability. We can partial solve the problem by re-weighting the charter school applicants so that their grade composition looks like that of the traditional public schools (essentially down-weighting applicants to low grades and up-weighting applicants to higher grades). This only partially solves the problem because applicants to higher grades, who apply only after having experienced the traditional public schools and presumably not found a perfect fit, are fundamentally somewhat different than applicants to lower grades. In short, there four independent reasons to believe that comparisons of the proxies between the charter schools and traditional public schools are problematic and must be interpreted with caution.

The bottom panel of Table 8 shows that, at the time they apply, 91.1 percent of charter school applicants are certified for free or reduced-price lunch. If we adjust this number so that the applicants have the same grade composition as the traditional public schools, it becomes 93.0. 86.6 percent of composite comparison school students are certified for free or reduced-price lunch and the parallel number for the New York City traditional public schools is 73.6 percent. In summary, on free and reduced-price lunch certification, applicants are fairly similar to the traditional public schools from which the charter schools draw (we cannot say more with any confidence) but the applicants are almost certainly poorer than average student in New York City. The certification difference of 17 to 19 percentage points is so large that it is implausible that correcting the multiple measurement problems would change its sign.

Table 8 also shows that, at the time they apply, 8.1 percent of charter school applicants participate in special education. If we adjust this number so that the applicants have the same grade composition as the traditional public schools, it becomes 11.1. This number is close to the composite comparison school's number (11.5) and the New York City number (12.6), and thus it appears that applicants are fairly similar to the traditional public schools from which the charter schools draw and to New York City overall. We cannot say more with any confidence given the multiple measurement problems.

Finally, Table 8 shows that, at the time they apply, 2.6 percent of charter school applicants are classified as English Language Learners. If we adjust this number so that the applicants have the same grade composition as the traditional public schools, it becomes 4.2. 13.7 percent of composite comparison school students and 13.6 percent of New York City students are English Language Learners. Because even our most comparable number (4.2 percent) is still not representative of charter school 
applicants, we hesitate to conclude that charter schools appeal disproportionately to students who are proficient in English. However, we believe that evidence that reinforces this conclusion comes from the disproportionate appeal of charter school to black students who are more likely to be native English speakers than Hispanic students.

C. Comparisons of applicants to others on the basis of prior test scores

Table 9 has the approximately the same format as Table 8, but it shows applicants' test scores from prior to their attending a charter school or staying in the traditional public schools. In other words, it is an attempt to provide an answer to the question of whether charter schools disproportionately draw low or high achievers. Unfortunately, the non-representativeness of applicants with prior test scores is far worse than the non-representativeness of applicants with time-of-application proxies. Only 36 percent of charter school applicants have prior test scores recorded because, given the lack of testing before third grade, a student must be applying to the fourth grade or a high grade in order to have been tested.

The top panel of Table 9 shows that this 36 percent of applicants are highly non-representative. The indicators (intended grade of entry, gender, race, and ethnicity) have their limitations, but they are nevertheless telling. All but one of the indicators are statistically significantly different for the students with and without prior test scores, and some of the group differences are very large in magnitude. Among students with prior test scores, about 56 percent are black and 37 percent are Hispanic. Among students without prior scores, 66 percent are black and 24 percent are Hispanic. Much more important, the average grade of intended entry is 5.7 for students with prior test scores but only 1.9 for students without them. This nearly four year difference in grade of entry is a serious problem because it means that the typical student with prior test scores has considerable experience in the traditional public schools when he decides to apply to a charter school. It is likely that he does not fit well in the traditional public schools but we do not know in what way. He might be less motivated than his classmates, more motivated, on an unexpectedly bad growth trajectory, on an unexpectedly good one. We can be fairly sure that these late grade applicants are not a random sample from their traditional public schools. In contrast, the applicants without prior test scores are so young that their parents have little information on which to decide that they do or do not fit well in the traditional public schools. Thus, it is reasonably likely that they are a random draw from their traditional public schools. In short, it is simply impossible to extrapolate from the applicants with prior test scores in order to make reasonably precise comparisons between the prior test scores of the average charter school applicant and the average New York City public school student.

The bottom half of Table 9 shows prior test scores for what they are worth. The scores are in standard score form and the scores for the composite comparison school and New York City public schools overall are from 2004-05 since this is the modal prior year for applicants. All of the standard 
scores for New York City overall are zero since the scores are standardized on the city-wide mean and standard deviation. Among charter school applicants who have prior test scores, the average standard scores in math are -0.10 in grade three, 0.02 in grade four, -0.01 in grade five, -0.004 in grade six, -0.25 in grade seven, and -0.001 in grade eight. The reading scores are similar. Composite comparison school students have average standard scores in math of -0.34 in grade three, -0.24 in grade four, -0.31 in grade five, -0.13 in grade six, -0.20 in grade seven, and -0.25 in grade eight. The reading scores are similar. In other words, the average composite comparison school student has lower scores than the average New York City student, but we have no way of comparing the average charter school applicant to the average composite comparison school student.

\section{Empirical Methodology for the Lottery-Based Analysis of Achievement}

In the previous section, we described numerous problems that make it hard to compare charter applicants to other students in the traditional public schools. None of these problems affect the achievement analysis that we now describe because the analysis is based entirely on applicants. The essential strategy is a comparison of students who are lotteried-in and lotteried-out of charter schools using instrumental variables regression. This strategy is fairly well known, so we will focus on aspects of it that are interesting in this application.

\section{A. Randomization and balanced lotteries}

Unlike some randomized studies in which there is one lottery that determines treatment or control status, there are 725 lotteries in our data. This is because, each year, each school holds a lottery for each grade in which it has space but is oversubscribed. Assignment is random within a lottery but a student's decision to participate in a certain lottery is non-random. In order to make use of all the within-lottery randomness and none of the between-lottery non-randomness, we include lottery fixed effects in all regressions.

The logic of randomization is that, owing to the law of large numbers, the average lotteried-in and lotteried-out students should not only be comparable on observable characteristics but also on unobservable ones. We hypothesize that lotteries that are balanced on the basis of students' observable characteristics are also more to be balanced on the basis of their unobservable characteristics. For this reason, we test each lottery for balance on the observable covariates prior to including it in the analysis. This is a conservative assumption in that we are relying solely on the within-lottery randomization and 
not the tendency of one unbalanced lottery to offset another across lotteries. ${ }^{20}$ Although results based only the balanced lotteries are the most credible, we also show results based on all lotteries as a specification test.

To test for balance, we use Hotelling's $\mathrm{T}^{2}$ test, which is the analog to the t-test when multiple variables are considered simultaneously. We use all available pre-determined student characteristics: gender, race, ethnicity, certification for free and reduced-lunch at the time of application, participation in special education at the time of application, classification as an English Language Learner at the time of application, and prior test scores. We use the classic fix of setting these variables equal to zero when they are missing and including an indicator for their being missing. Thus, we are also testing whether the lotteried-in and lotteried-out are balanced on having missing data.

B. Students with slightly complex lottery participation

Some students participate in multiple lotteries and are lotteried-in at one school and lotteried-out at the others. For this overall analysis, we treat such students as having been lotteried-in at the school at which they enroll and keep them as lotteried-out students in the other schools' lotteries only for the purpose of testing balance. We do not treat them, post-lottery, as though they had been lotteried-out of those other schools and were attending traditional public schools as a result. Some students participate in multiple lotteries and are lotteried-out of all of them. They may therefore serve as controls for treated students in more than one lottery. To account for this phenomenon, we estimate robust standard errors clustered at the student level (as opposed to the application level).

If a student applies to a charter school and has a sibling already enrolled at that charter school, he is given a place in the grade to which he applies if there is space. That is, he is placed ahead of the lottery. (This is standard treatment for siblings in many magnet, intra-district choice, and desegregation programs.) If a larger number of siblings applies than there are places, a lottery is run among the siblings. As a practical matter, this does not occur in intake grades but does occasionally occur in non-intake grades where the number of vacancies can be very small. We treat a student who is admitted on the basis of his sibling's enrollment as having been lotteried-in with his sibling-that is, he counted as lotteried-in. If a student has a sibling and participated in an all sibling lottery, he is lotteried-in if he was lotteried-in in that lottery and lotteried-out otherwise. We show a specification test for siblings below, and logic

${ }^{20}$ If each of our lotteries was an independent draw from the same population, we would rely equally on balanced and unbalanced lotteries. We are not confident making such an assumption, however. 
suggests that sibling priorities would, if anything, slightly depress the estimated charter school effect. ${ }^{21}$ C. Treatment, the intention-to-treat, and the localness of the average treatment effect

In our analysis, the treatment variable is the number of years that a student has been enrolled in a charter school. This is the most natural treatment variable but it does assume that the effect is a function of the length of the treatment, as opposed to the mere fact of treatment (a one-time effect of enrolling in a charter school). We plan, in future reports, to show specification tests that allow the treatment variable to enter non-linearly so that if the effect of charter schools first increased (decreased) with time elapsed and then hit a plateau, we might see this. Unfortunately, we do not yet have sufficient variation in time elapsed for such tests. Among the observations that are useful for estimation (see below), almost 40 percent are for a student's first post-lottery year, 27 percent are for a student's second post-lottery, 19 percent are for a student's third post-lottery year, and the remainder are spread thinly over the fourth through the sixth post-lottery years.

The intention to treat variable is the number of years that a student would have spent in charter school if he complied fully with assignment based on the lottery. That is, for a student who is lotteried-in, the clock starts ticking with the fall of the school year in which he could enter a charter school and it continues ticking until such time as he would have reached the charter school's final grade.

We instrument for the treatment variable with the intention to treat variable to obtain a treatment on the treated effect. As is well known, the resulting estimator is local to the type of student who is a complier-that is, students who, when offered a place in a charter school, enroll. In some applications, having an estimator that is local to compliers is problematic because we would like to be able to think about the effect that treatment would have if it were extended to those who would be non-compliant. In the case of charter schools, however, an estimate that is local to compliers is exactly what we want. It is part of the whole charter school idea that only students who want to charter schools should attend them.

${ }^{21}$ Suppose that a family decides that it is interested in a charter school and puts their oldest child in a lottery. If he is lotteried-in, so in all likelihood are all of his younger siblings as long as they apply to the intake grade. Suppose that if he is lotteried-out, the family does not have the younger siblings apply when they reach the relevant age because the oldest child is already installed in a traditional public school and the family wants to keep the children together. This scenario would not pose a problem for the study.

Alternatively, suppose that even though their oldest child is lotteried-out, the family continues to enter younger siblings in lotteries when they reach the relevant age. Also, suppose that if a younger sibling gets lotteried-in, the older sibling(s) will then use sibling priority in the following year to enroll in the charter school if their non-intake grades have space. This scenario could be a problem for the study because it gives larger families "more bites at the apple". Then, if family size were correlated with outcomes, that correlation could be confounded with the charter school effect. Family size is generally found to be negatively correlated with student achievement so we would expect the problem to bias downward the estimated effect of charter schools on achievement. 
What we want to be to do is extrapolate the results to other students who, like the compliers, want to attend charter schools and have needs similar to those of the students who apply to New York City charter schools now. We would argue against the extrapolation of the results to, for instance, students who are from affluent white or Asian households with two parents who live in an advantaged neighborhood.

In most randomized assignment studies, there are two types of non-compliance: students can decline the opportunity to enroll in a charter school even though they are offered a place ("decliners") and students enroll in a charter school even though they are not offered a place ("defiers"). There are no defiers in our study so far as we know. That is, there should not be and we do not observe any student attending a charter school who was reported as having been lotteried-out. We do observe decliners and it is precisely to account for them that we use instrumental variables to estimate the treatment on the treated effect. We show some data below to investigate the question of how decliners compare to compliers and the lotteried-out.

\section{The estimating equations}

In summary, the implied second stage of our basic instrumental variables procedure is

$$
A_{i j t}=\beta_{1} \text { Treatment }{ }_{i j t}+X_{i} \boldsymbol{\beta}_{2}+I_{j}^{\text {lottery }} \boldsymbol{\beta}_{\mathbf{3}}+\boldsymbol{I}_{g}^{\text {test grade }} \boldsymbol{\beta}_{4}+\boldsymbol{I}_{t}^{\text {sehool year }} \boldsymbol{\beta}_{5}+\epsilon_{i j t}+\epsilon_{i}
$$

where $A_{i j t}$ is the year $t$ achievement (standard score) of student $i$ who participated in lottery $j$; Treatment $t_{i j t}$ is his time spent in charter school by year $t$; the vector $\boldsymbol{X}_{\boldsymbol{i}}$ contains the set of pre-determined covariates that describe student $i,{ }^{22}$, the vector $\boldsymbol{I}_{\boldsymbol{j}}$ is an exhaustive set of lottery fixed effects (note the lack of another constant), $\boldsymbol{I}_{\boldsymbol{g}}^{\text {grade }}$ is a set of grade-of-test fixed effects, and $\boldsymbol{I}_{\boldsymbol{t}}^{\text {school } \text { year }}$ is a set of school year fixed effects, $\epsilon_{i j t}$ is the observation level error term, and $\epsilon_{i}$ reminds us of the robust standard errors clustered at the student level. Note that the grade-of-test and school year fixed effects are nearly superfluous because the test scores are standardized already using the grade-by-year specific means and standard deviations. The The implied second stage of the instrumental variables procedure is

$$
\text { Treatment }_{i j t}=\alpha_{1} \text { Intention-to-treat }{ }_{i j t}+X_{i} \alpha_{2}+I_{j}^{\text {lottery }} \alpha_{3}+I_{g}^{\text {test grade }} \alpha_{4}+I_{t}^{\text {school year }} \alpha_{5}+v_{i j t}+v_{i},
$$

where Intention-to-treat $t_{i j t}$ is the intention-to-treat variable defined above, $\mathbf{v}_{i j t}$ and $v_{i}$ are error terms parallel to those in the implied second stage, and all other variables are as defined above.

E. A comment on alternative methods of assessing charter school students' test scores

In Hoxby and Murarka (2007), we consider methods other than lottery-based methods of

22 The list is given in the text in the discussion of the Hotelling $\mathrm{T}^{2}$ test for balance. 
assessing charter school students' test scores. We conclude that modern methods that essentially rely on comparison to public school students who may or may not be applicants, such as matching and the propensity score, appear promising but need to be validated by lottery-based results because the researcher has so much discretion about how he remedies the selection problem. We conclude that pure value-added methods, in which a researcher compares the a student's rates of gain before and after applying to charter school, are not at all appropriate in practice. This is because such methods require that a student has been tested for at least two years in the traditional public schools prior to applying. Thus, the sample to which the results are local is even more non-representative than the 36 percent of students whom we identified above as having prior test scores. We required them only to have a single prior test score and yet found that they were obviously non-representative. If we require them to two prior test scores so that we can compute a pre-application gain, our sample falls to a mere 16 percent of the applicants.

Moreover, the problem is not merely one of non-representativeness (which might merely cause us to estimate an effect that could not be extrapolated). The problem is the classic program evaluation problem. Just as people are motivated to join training programs only when something happens that usually makes their past gains uninformative about their future gains in the absence of training, students are motivated to apply to charter schools only when something happens that usually makes their past gains uninformative about their future gains in the absence of the charter school. Applying pure valueadded analysis is as naive in the charter school context as it is in the training context. ${ }^{23}$

\section{The Lotteries and their Usefulness for Analysis of Achievement}

In 2004 and 2005, the years for which we have the most complete application data, about 94 percent of applicants participated in lotteries. About 91 percent of all recorded applicants participated in lotteries. (These percentages can be derived from the numbers in Table 5.)

The left hand panel of Table 10 shows the predetermined characteristics of applicants who are lotteried-in and the differences between them and the compliers, decliners, and lotteried-out students. Lottery fixed-effects are removed before the differences are computed so that we are examining intralottery differences. There are no statistically significant differences at the 95 percent level between the lotteried-in and lotteried-out. The few statistically significant differences between compliers and decliners are small: compliers are very slightly more likely to be female and less likely to participate in

${ }^{23}$ There is an enormous literature on this problem, but a seminal paper that is very useful for thinking about pure value-added analysis is Ashenfelter and Card (1985). 
special education or English Language Learners. Differences between compliers and decliners are useful for thinking about the population to which the estimates are local, but the differences in question are so small in magnitude that one can continue thinking about the applicants as the local group.

The overall similarity of the lotteried-in and lotteried-out does not mean that every individual lottery is balanced on the predetermined characteristics. We would expect that some lotteries would be unbalanced in one way and others in another way, cancelling out since there are large number of lotteries. Of course, the same cancelling-out might be expected of the unobservable variables. Thus, as mentioned above, we might proceed with using all the data from students who participate in lotteries, and we do show specification tests with these results. However, since randomization occurs at the lottery level and we cannot confidently assume that each of our lotteries is an independent draw from the same population, it is more conservative only to assume that individual lotteries that are balanced on the predetermined characteristics are balanced on the unobservable variables.

Using Hotelling's $\mathrm{T}^{2}$ test set at the 95 percent level, we find that 86 percent of students who participated in a lottery in 2005-06 were in a lottery identified as balanced and that, if we exclude siblings, the percentage is 94 percent. This is about what we would expect from random lotteries. (Siblings can cause unbalancedness because they were not really lotteried-in in the lottery in which they appear. As noted before, it is more correct to think of families participating a lottery when their oldest child applies to a charter school.)

The applicants who are lotteried-in after participating in balanced lotteries are not statistically significantly different from all applicants who are lotteried-in. Among applicants who participated in balanced lotteries, there are no statistically significant differences between the lotteried-in and lotteriedout, and there are same few statistically significant differences between compliers and decliners: compliers are slightly more likely to be female and less likely to participate in special education or English Language Learners. In short, it appears that those who participated in balanced lotteries are representative of all lottery participants.

Table 11 shows the availability of test data from participants in balanced lotteries. The rows are the tests, the columns are the school years in which the tests were taken, and the cells in the table show the number of test-takers. For example, the uppermost left-hand cell shows that 3,111 students who had participated in balanced lotteries took the third grade tests in 2005-06. The vast majority of these students participated in kindergarten lotteries. (That is, the cell does not show how many students participated in balanced third grade lotteries in 2005-06.) Note that many students who participated in balanced lotteries would not have reached a test-taking grade by 2005-06.

Looking at the right-hand column of Table 11, we see that when we use all of the years available, 
we have between about 3000 and 7800 observations for each of the grade three through eight tests. However, we have fewer than 100 observations for each of the Regents Examinations. This is simply because so few applicants who participated in balanced lotteries for which we have data are in high school by $2005-06 .{ }^{24}$ It is fairly obvious that we have insufficient data to generate meaningful results from the Regents Examinations, but we show below what we obtain.

\section{Lottery-based Analysis of Test Scores}

Tables 12 and 13 present the main test score results of this report. In each case, our preferred specification is in the far left-hand column, and specification tests are shown in the remaining columns. The top row shows the coefficient on time enrolled in the charter school--the treatment variable, and the remaining rows provide details on the specification.

New York City's charter schools raise their third through eighth graders' math scores by 0.09 standard deviations for every year they spend in the school. These gains are relative to whatever gains the students would have been expected to make in the traditional public schools, had they been lotteried-out. The result is statistically significant with a p-value less than 0.001 . Because most of the observations of the treatment variable are between one to three years and all of them are between one to six years, this result should not be extrapolated beyond four years of enrollment in charter school.

When we change the set of covariates for which we control, the coefficient moves only a little: up to 0.10 or 0.11 . (See Table 12.) We expect only a small amount of movement with an estimate based on randomization. Indeed, the movement implicitly tests whether randomization has actually balanced the lotteried-in and lotteried-out students. Excluding students who have sibling priority and adjusting for attrition (with standard upweighting of students whose observable characteristics are the same as the attritors) hardly affect the coefficient. Including all lotteries regardless of whether they are balanced reduces the coefficient to 0.06 , but it remains statistically significantly different from zero with very high confidence.

${ }^{24}$ Two of the charter schools that currently offer high school grades have opened or rolled up to these grades very recently and provide only a little data. The two charter schools that might seem to have considerable numbers of high school aged students in 2005-06 do not actually generate much data on Regents Examinations from students who participated in balanced lotteries. Wildcat Academy is a school for likely drop-outs and it has not run lotteries for most grades in most years (although it has run lotteries recently). Renaissance Charter School is a conversion school that offers kindergarten through the twelfth grade. Most of its current high school aged students were admitted in its pre-conversion days when it admitted students according to district priorities as well as a lottery. In any case, the school did not archive application data beyond one year so that most of the Renaissance applicants who participated in available balanced lotteries are currently in grades kindergarten through eight. 
New York City's charter schools raise their third through eighth graders' reading scores by 0.04 standard deviations for every year they spend in the school. These gains are of course relative to whatever gains the students would have been expected to make in the traditional public schools, had they been lotteried-out. The result is statistically significant with a p-value of 0.02 . Again, we would not extrapolate this result beyond four years of enrollment in charter school.

When we change the set of covariates for which we control, the coefficient moves between 0.04 and 0.07. (See Table 13.) Again, the small amount of movement implicitly tests whether randomization has actually balanced the lotteried-in and lotteried-out students. Excluding students who have sibling priority and adjusting for attrition (with standard upweighting of students whose observable characteristics are the same as the attritors) hardly affect the coefficient. The coefficient remains at 0.04 when we include all lotteries regardless of whether they are balanced.

New York City most often reports test scores in terms of the state's performance levels or scale scores. In 2005-06, depending on the grade, a standard deviation was 41 to 43 scale score points in math and 39 to 41 scale score points in reading. In the same year, depending on the grade, a student's math scale score had to rise by an average of 32 points to go from the top of the Performance Level 1 range (not meeting learning standards) to the bottom of the Performance Level 3 range (meeting learning standards). The equivalent required rise in a student's reading score was 44 points. See Appendix Figures 1 and 2 .

Thus, the principal effects estimated in Tables 12 and 13 can be translated as students' math scale scores rising by 3.75 to 3.98 points (depending on the grade) and their reading scale scores rising by 1.53 to 1.61 points (depending on the grade) for every year they spend in charter schools. Alternatively, one can translate them as students' math performance rising by about 12 percent of a performance level and reading performance rising by about 3.5 percent of a performance level for every year they spend in charter schools.

There are several possible explanations for charter schools' effects being larger and more precise in math than in reading. The most likely explanation, we believe, is that schools largely control math education but that both families and schools exert influence over reading. If, for instance, the families of lotteried-in and lotteried-out students had the same effect on reading and families controlled half the gains in reading, then the difference between the estimated math and reading effects would be rather fully explained.

We have explored a variety of breakdowns of the principal effects estimated above: effects by grade of entry, by grade of the test, and by the school year in which the test was administered. None of these breakdowns proved to be meaningful in the following sense: the standard errors increased 
considerably and the point estimates displayed no pattern beyond being centered on the principal effects already described. We conclude that more data are needed to make such breakdowns useful. ${ }^{25} \mathrm{We}$ also broke down the principal effects by the student's gender and being black non-Hispanic versus Hispanic. (There are too few applicants who belong to the other racial groups to analyze them.) The results, shown in Table 14, indicate that the charter schools' effect is extremely consistent across males and female students and across black and Hispanic students. Not only are the coefficients not different across gender or race/ethnicity in a statistical sense, they are very similar in an educational sense.

In Table 15, we show the Regents Examination analysis available at this time. Prior to seeing the results, we decided to show effects only for tests in which we had sufficient power to produce standard errors that were less than a standard deviation on the test. We end up showing just the coefficient for Math A, a test focusing on basic algebra and geometry that is recommended for tenth graders but taken by some students in our sample as early as the eighth grade. The coefficient is positive but has such a large standard error that its $\mathrm{p}$-value is 0.76 .

\section{Variation in Lottery-based Estimates of Effects Among Charter Schools and the Associations between these Effects and Schools' Policies}

We are able to estimate school-specific effects on the grade three through eight tests for 32 individual charter school--that is, all of the charter schools that have students in grades three through eight. The remaining three test-taking schools offer only high school grades. However, because the schools are of different ages and sizes, the precision of the individual schools' effects varies greatly.

About one third of individual charter schools have estimated effects that are so noisy that it is not worthwhile comparing them as point estimates with other schools' estimated effects except in a statistical setting where we can formally account for precision. (We do this below.) Visual inspection of the point estimates is useful for the other two thirds of the individual charter schools' estimated effects. (We view

${ }^{25}$ We were initially surprised not to find that the breakdown on grade-of-entry was important. This is because Hoxby and Rockoff (2004), using similar lottery-based methods on Chicago charter schools, found that students who entered in early grades experienced significant positive effects but that effects for late-grade entrants varied substantially with the covariates, had large standard errors, and were often not statistically significantly different from zero. We suspect that Chicago's grade-of-entry effects are much more systematic than New York's because the main intake grade in Chicago is kindergarten for nearly all charter schools. Moreover Chicago's charter schools are far more homogeneous than the New York City's, so that it is reasonable to find an effect that holds across schools. In New York City, effects may be more likely to hold across dimension within a charter school than within a dimension across charter schools. Finally, Hoxby and Rockoff do not limit their analysis to balanced lotteries, and numerous lotteries for late grades of entry were unbalanced. 
an individual charter school's estimated effect as too noisy to contribute to the visual inspection if is not only statistically insignificant but if also its standard error is such that an effect of 0.1 standard deviations would be statistically insignificant at the 95 percent level. $)^{26}$

Figure 5 shows the range of estimated effects of New York City's charter schools on math in grades three through eight. We created this figure by estimating an effect on math for each school separately. Then we plotted the distribution of the schools' effects on students. That is, the distribution of effects is representative of the charter school students of New York City. We smoothed the distribution slightly so that readers could not pick out the effects of individual charter schools. The distribution of estimated math effects of New York City's charter schools (the shaded distribution with three peaks) shows that about 19 percent of charter school students attend a school that is estimated to have a positive effect on math that is greater than 0.3 standard deviations. About 56 percent of charter school students attend a school that is estimated to have a positive effect on math that is between 0.1 and 0.3 standard deviations. About 18 percent of charter school students attend a school that is estimated to have an effect on math between 0 and 0.1 standard deviations, and the remaining six percent of students attend a school that is estimated to have an effect on math that is negative.

Figure 6 shows the parallel distribution for reading. About 9 percent of charter school students attend a school that is estimated to have a positive effect on reading that is greater than 0.3 standard deviations. About 71 percent of charter school students attend a school that is estimated to have a positive effect that is between 0.1 and 0.3 standard deviations. About 13 percent of charter school students attend a school that is estimated to have an effect between 0 and 0.1 standard deviations, and the remaining eight percent of students attend a school that is estimated to have an effect that is negative.

It is natural to ask whether charter schools' estimated effects are systemically associated with certain policies. At this time, we have very limited ability to answer this question because we have 64 observations of schools' effects in 32 clusters of two non-independent effects. That is, we have 32 schools and two subjects, and the effect in each subject is potentially informative but not independent of the same school's effect in the other subject. Nevertheless, we investigate whether certain school policies are associated with positive effects on achievement using multiple regression. To account for

${ }^{26} \mathrm{We}$ are not saying that the effect of attending a charter school is a reasonably precisely estimated zero for the remaining 36 percent of students. We are saying that our visual inspection of point estimates--a form of analysis that does not make it easy to consider precision--is helpful only with point estimates that are reasonably precise. We include all charter schools in the statistical analysis below where we can explicitly account for precision. Of course, we also include all applicants' achievement in the estimates of the average charter school effects $(0.09$ standard deviations in math, 0.04 standard deviations in reading) described above. 
heteroskedasticity, we give weight to a school's estimated effect commensurate with the precision of the estimate. We include subject fixed effects, and estimate robust standard errors clustered at the school level to account for the non-independence of each schools' two estimated effects.

We have no way to estimate how charter schools' policies causally change their effects on achievement. We can describe only associations between policies and achievement effects, and the distinction between association and causation is very important in practice in the charter school context. For instance, suppose that charismatic school leaders were a key cause of positive achievement effects, and suppose that charismatic leaders just happened to like long school years. We cannot measure charisma, but we can measure the length of the school year. Therefore, we might find an association between a long school year and positive achievement effects even if the charisma, and not the long school year, caused higher achievement. A school that lengthened its school year would be disappointed in the results, not realizing that what it had really needed to do was to hire a charismatic leader.

Another problem is multicollinearity. Charter schools tend to adopt loose packages of policies. For instance, schools that adopt a long school year very often also adopt a long school day. Appendix Table 1 shows the correlation matrix. If one policy in a package is measured well (in the sense that its variation accurately represents variation in the package) and other policies in the package are measured poorly, an association may load on the well-measured policy even it is not essential to the package. In short, there are three good reasons (the need for more data, the lack of causal effects, and multicollinearity) to be cautious about the associations between policies and charter schools' estimated effects. We would not be surprised to find that some associations change substantially in next year's report.

Table 16 shows the results of the regression analysis. We find that a charter school's years in operation has an association with achievement effects that is not statistically significantly different from zero. It is interesting to note, however, that if we do not control for policies and look at the univariate association between a charter school's years in operation and its achievement effect, we find that older schools have more positive achievement effects. The fact that this correlation disappears when we control for policies suggests that the reason older schools have more positive achievement effects is that they adopt more effective policies. A charter school's operating agency type does not have association with achievement effects that is statistically significantly different from zero. It is interesting to note, however, that if we do not control for a school's policies and we look at the association between a charter school's agency type and its achievement effect, we find statistically significant correlations. The fact that these correlations disappear when we control for policies indicates to us it is not agency type that matters but the policies that schools adopt. 
A long school year is associated with positive achievement effects, and the coefficient indicates that schools with years that are ten days longer are associated with achievement effects that are 0.2 standard deviations higher. This is an association of considerable magnitude, and a ten day difference is quite common. (Twelve days is the standard deviation in the length of the school year among charter schools.) However, it is important to note that a long school year is correlated with several other policies and this multicollinearity should make us cautious about interpreting the variable literally. A long school day and Saturday School have associations with achievement effects that are not statistically significantly different from zero, but these policies are strongly correlated with a long school year (and the year is probably better measured). The multicollinearity problem is such that readers may wish to think of the package of a long school year, long school day and Saturday School rather than focus on the long school year by itself.

Optional after-school programs, most math curricula, and most reading curricula do not have associations with achievement effects that are statistically significantly different from zero. (Note that omitted curricular category is a mixture of other programs, each of which is adopted by a few schools at most. We describe the more common curricula in the appendix.) However, Everyday Math and Open Court reading have negative and statistically significant associations with achievement effects. We strongly discourage readers from interpreting their coefficients as causal effects since an equally if not more plausible interpretation is that these are curricula that schools adopt when their students struggle with learning deficits.

Class size has an association with achievement effects that is estimated with a fair degree of precision and that is not statistically significantly different from zero. Interestingly enough, larger class size is often found in packages with longer school years. We surmise that if a school wants to adopt a longer school year, it needs to find room in its budget. By raising class size by, say, four students, a school may be able to free up twenty percent of its budget, allowing an expansion of the school year.

The coefficients on internal evaluations, school uniforms, a dress code, the No Broken Windows disciplinary policy, and a parent contract all have such large standard errors that the coefficients do not provide evidence one way or the other about their associations with achievement. That is, these are not precisely estimated zero effects. We need more data, especially since there is very little variation among charter schools in the adoption of the first three policies (they are very common).

The policy of reserving one or more seats on the board for parents and a school's number of leaders both have positive associations with achievement effects that are close to the margin of being statistically significantly different from zero (the p-values are 0.116 and 0.163 ). There are a number of other school characteristics that we did not include in the regression because there was insufficient 
variation in their use among New York City charter schools. This highlights the importance of policy variation among the schools if we are to learn about associations. To the extent that the schools converge on a common set of policies, we will find it difficult to discern the associations.

Because the long school year is strongly positively associated with achievement and seems unlikely to be adopted because students are performing better than expected (that is, reverse causality and selection on positive unobservables seem unlikely), we plan to stay attentive to packages of policies that include a longer year, which can be as many as 220 days in New York City charter schools. 


\section{References}

Ashenfelter, O. and Card, D. 1985. "Using the Longitudinal Structure of Earnings to Estimate the Effect of Training Programs," The Review of Economics and Statistics, vol. 67.4 (November), pp. 648-60.

Burghardt, J., Silva, T., and Hulsey, L. 2004 “Case Study of National School Lunch Program Verification Outcomes in Large Metropolitan School Districts.” Special Nutrition Program Report Series, No. CN-04-AV3. Project Officer: Paul Strasberg. U.S. Department of Agriculture, Food and Nutrition Service, Office of Analysis, Nutrition and Evaluation, Alexandria, VA.

Center for Education Reform. 2007. Charter School Laws in the 50 States. Washington, DC: Center for Education Reform.

Cullen, J., and Rivkin, S. 2003. "The Role of Special Education in School Choice," in C. Hoxby, ed., The Economics of School Choice. Chicago: University of Chicago Press.

Hoxby, C., and Murarka, S. 2007. "Methods of Assessing Achievement of Students in Charter Schools," in ed. M. Behrens, Charter School Outcomes. New York: The Analytic Press.

Hoxby, C., and Rockoff, J. 2004. "The Impact of Charter Schools on Student Achievement," Harvard University working paper.

New York City Department of Education. 2007. Basic Education Data System [machine-readable data].

Ruggles, S., Sobek, M., Alexander, T., Fitch, C., Goeken, R., Hall, P., King, M., and Ronnander, C. 2007. Integrated Public Use Microdata Series: Version 3.0 [machine-readable data]. Minneapolis, MN: Minnesota Population Center [producer and distributor]. http://usa.ipums.org/usa/ (accessed July 2007).

United States Department of Agriculture, Food and Nutrition Service, Office of Analysis, Nutrition and Evaluation. 2003. School Food Authority Administration of National School Lunch Program Free and Reduced Price Eligibility Determination, CN-03-AV, by Paul J. Strasberg. Alexandria, VA.

United States Department of Commerce, Bureau of the Census. 2002. Census of Population and Housing Summary File 1 [machine-readable data]. Washington, DC. www.census.gov (accessed July 2006).

United States Department of Commerce, Bureau of the Census. 2002. Census of Population and Housing Summary File 3 [machine-readable data]. Washington, DC. www.census.gov (accessed July 2006). 
Figure 1

Map of New York City Charter Schools

2005-06

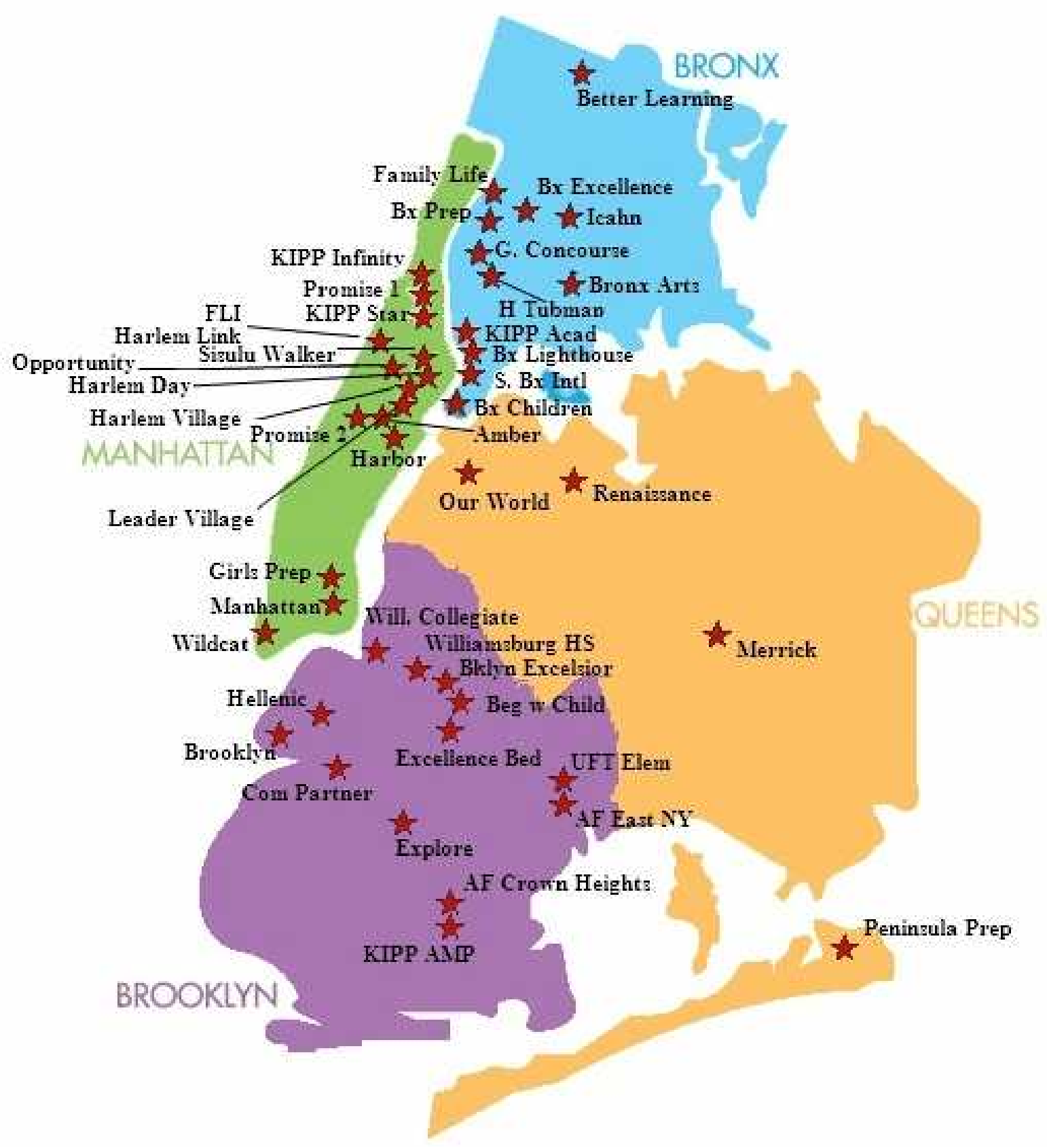


Figure 2

Authorizers of the New York City Charter Schools

an-

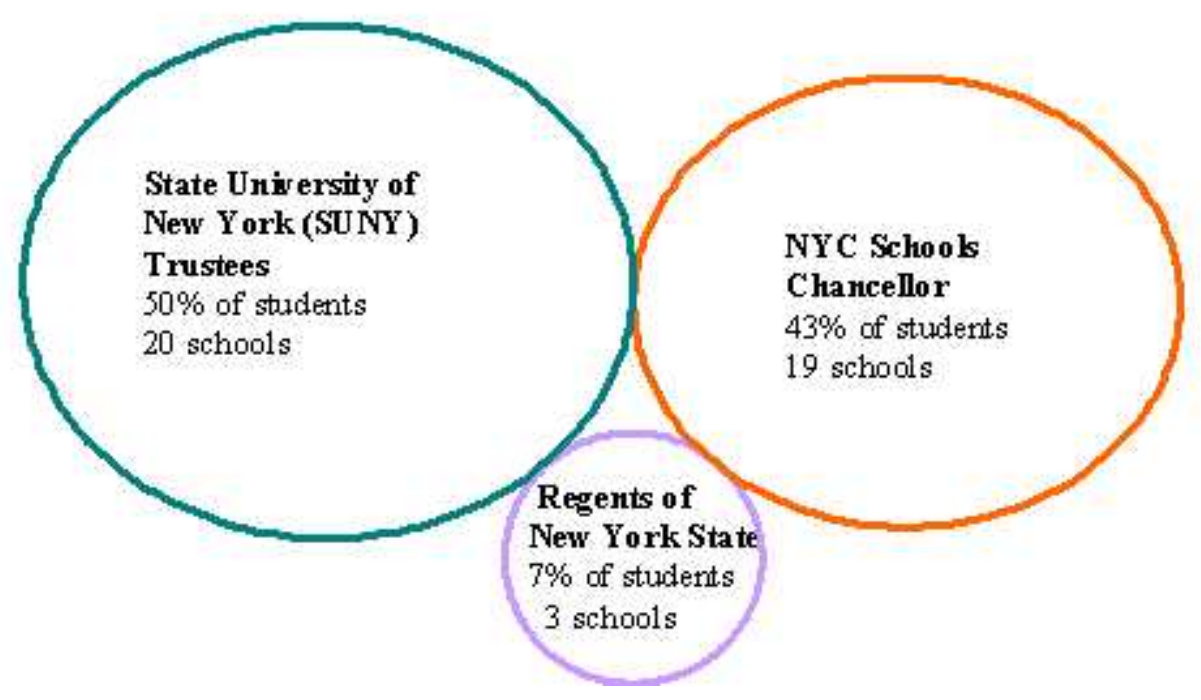

Figure 3

Operating Agencies of New York City Charter Schools

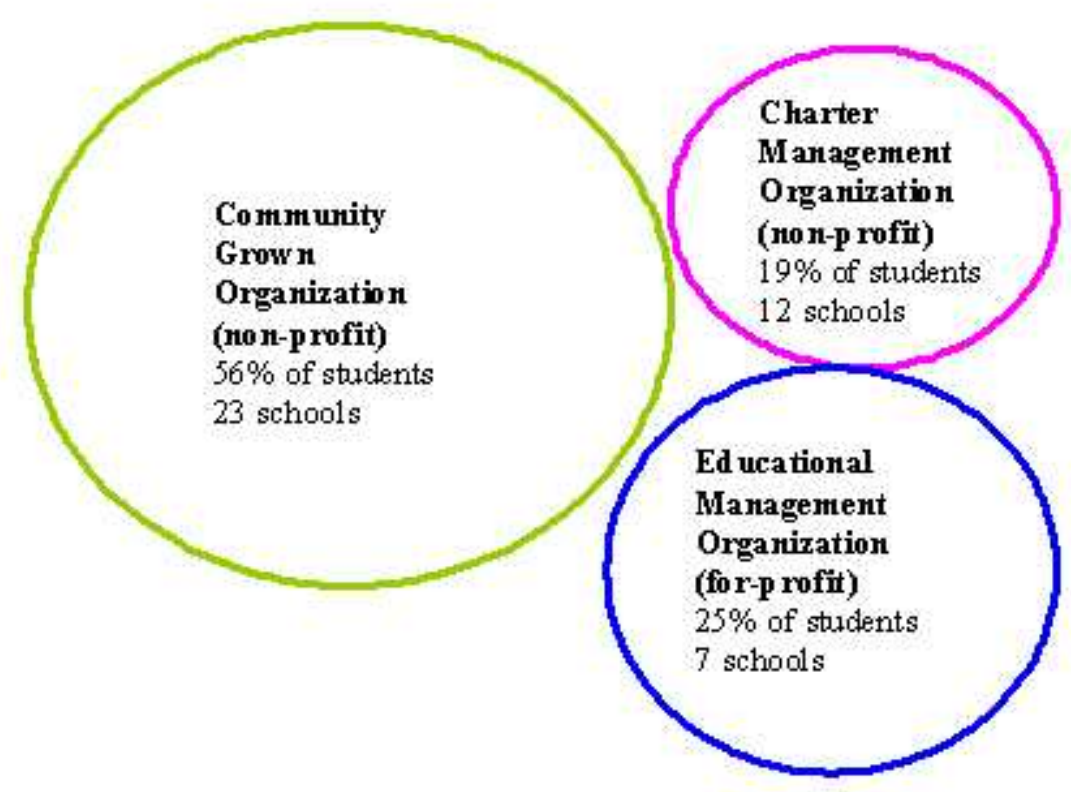


Figure 4

Approximate Missions of the New York City Charter Schools 2005-06

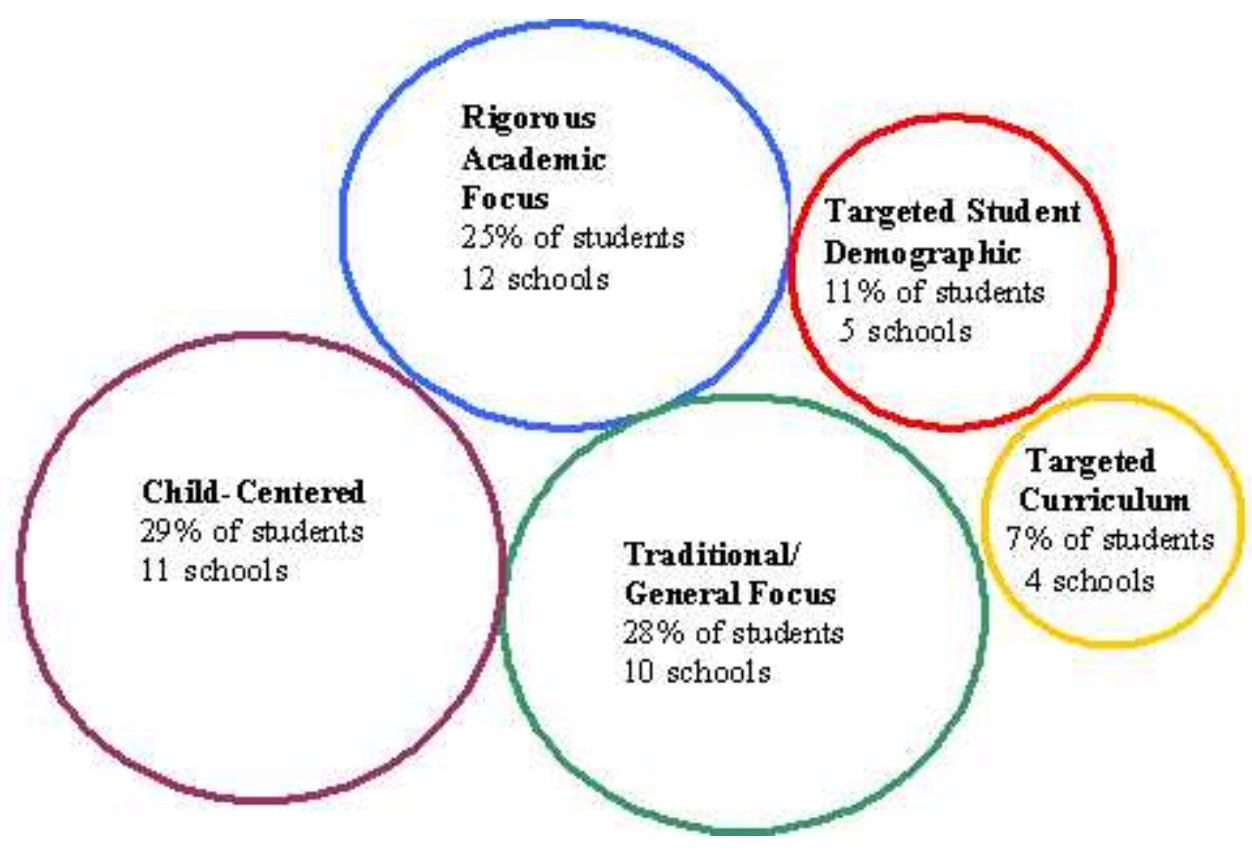




\section{Figure 5}

\section{Distribution of Charter School Effects on Mathematics (grade 3 through 8 tests)}

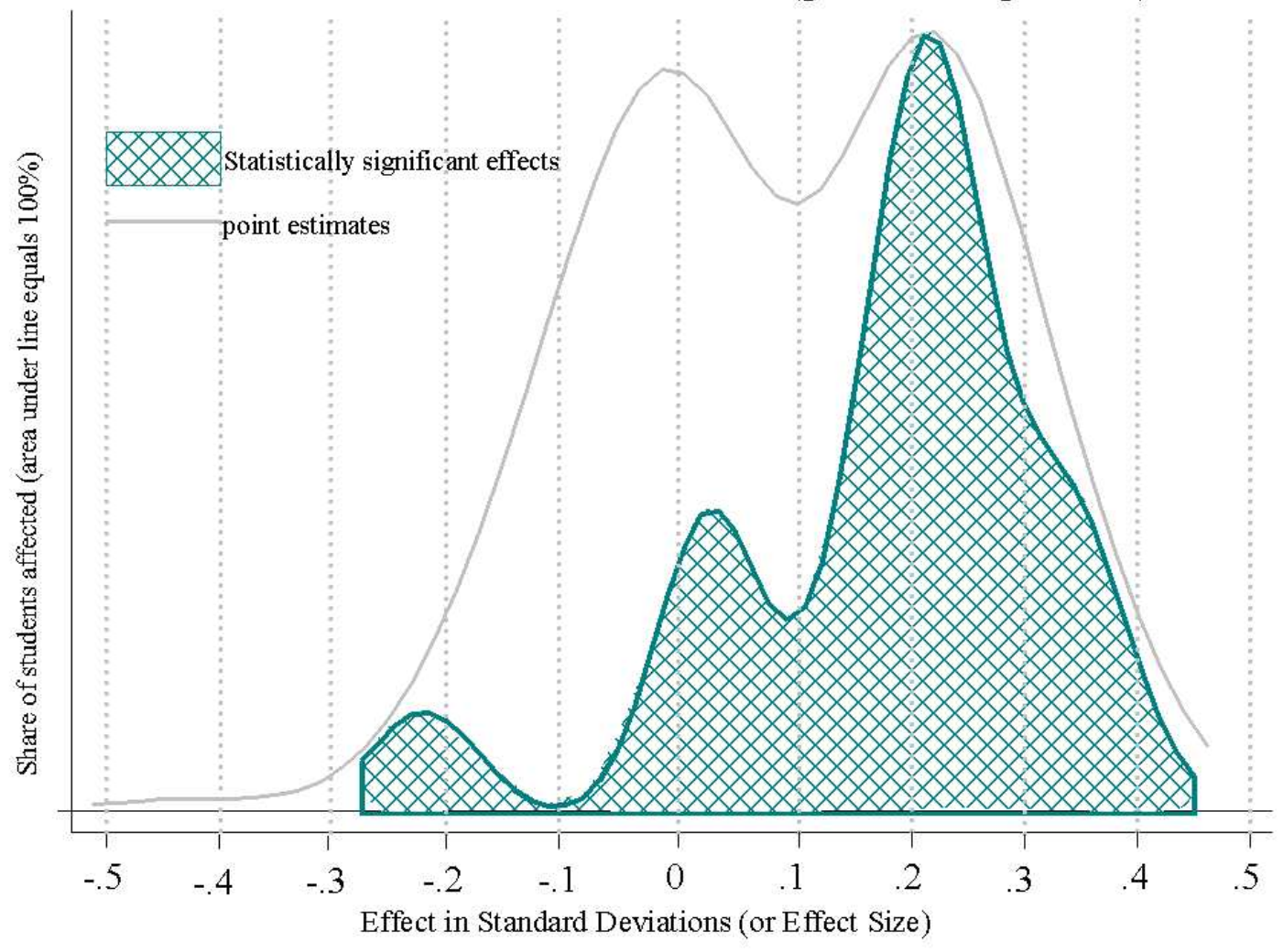

Notes: The shaded area shows the distribution of estimated effects of charter schools on math (grades three through eight) that are sufficiently precise that they are either statistically significantly different from zero or that an effect of 0.1 standard deviations would be statistically significantly different from zero with 95 percent confidence. The point estimates line includes some estimates that are very imprecise (so imprecise that the confidence interval includes implausibly extreme effects that are both negative and positive). 


\section{Figure 6}

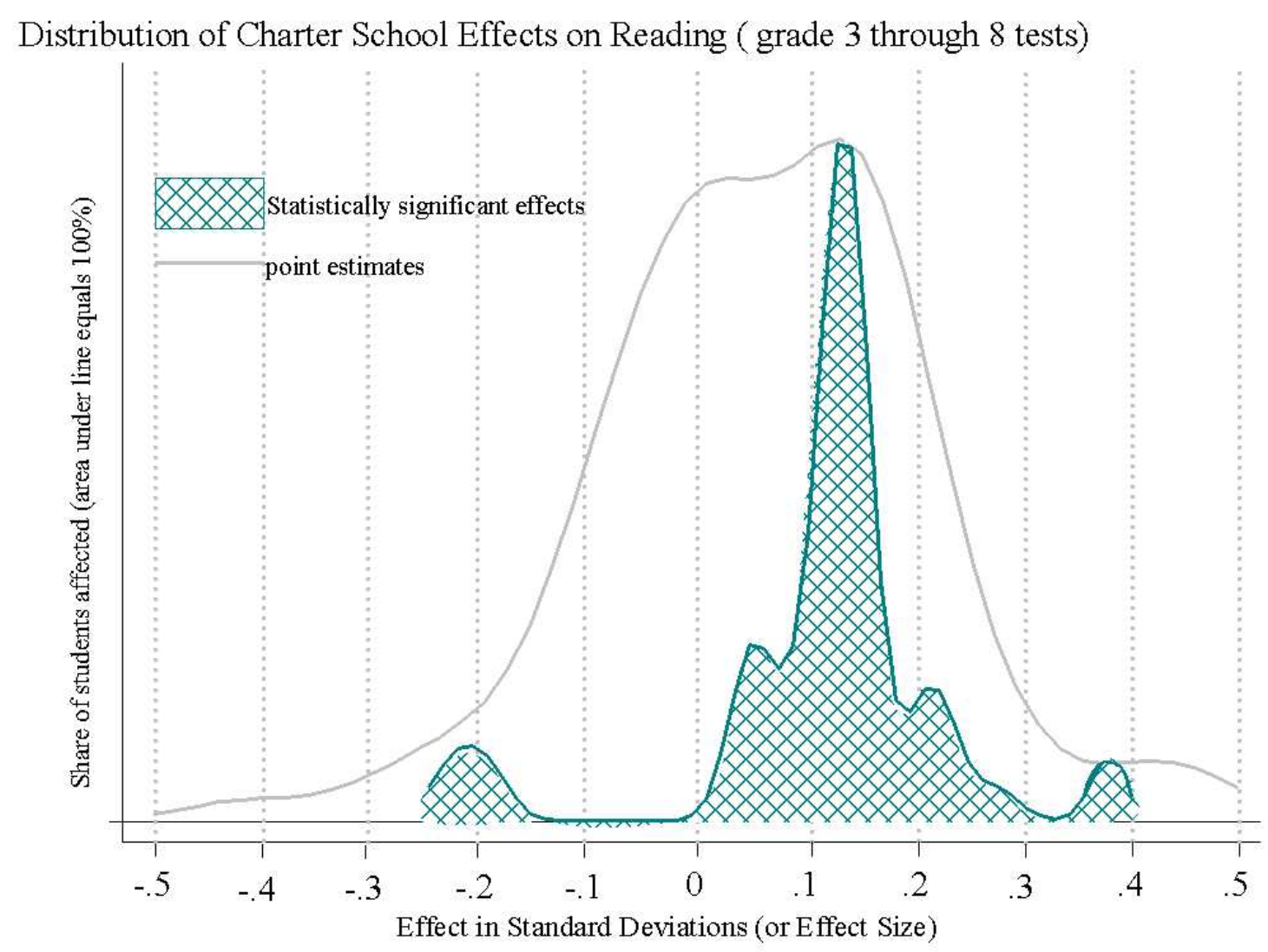

Notes: The shaded area shows the distribution of estimated effects of charter schools on math (grades three through eight) that are sufficiently precise that they are either statistically significantly different from zero or that an effect of 0.1 standard deviations would be statistically significantly different from zero with 95 percent confidence. The point estimates line includes some estimates that are very imprecise (so imprecise that the confidence interval includes implausibly extreme effects that are both negative and positive). 
Table 1

Number of Charter Schools and Grades Offered by Charter Schools in New York City

\begin{tabular}{llrrrrrrrrrrrrr}
\hline \multirow{2}{*}{$\begin{array}{l}\text { school } \\
\text { year }\end{array}$} & $\begin{array}{l}\text { \# of schools } \\
\text { open and in this } \\
\text { study }\end{array}$ & $\mathrm{K}$ & 1 & 2 & 3 & 4 & 5 & 6 & 7 & 8 & 9 & 10 & 11 & 12 \\
\hline $1999-00$ & 2 & 1 & 1 & 1 & 1 & 0 & 1 & 1 & 1 & 1 & 0 & 0 & 0 & 0 \\
$2000-01$ & 10 & 6 & 7 & 4 & $\mathbf{3}$ & $\mathbf{2}$ & $\mathbf{4}$ & $\mathbf{4}$ & $\mathbf{2}$ & $\mathbf{2}$ & $\mathbf{2}$ & $\mathbf{2}$ & $\mathbf{2}$ & $\mathbf{2}$ \\
$2001-02$ & 15 & 10 & 12 & 10 & $\mathbf{6}$ & $\mathbf{4}$ & $\mathbf{5}$ & $\mathbf{5}$ & $\mathbf{5}$ & $\mathbf{3}$ & $\mathbf{2}$ & $\mathbf{2}$ & $\mathbf{2}$ & $\mathbf{2}$ \\
$2002-03$ & 17 & 12 & 13 & 14 & $\mathbf{1 2}$ & 7 & 7 & $\mathbf{5}$ & $\mathbf{5}$ & $\mathbf{6}$ & $\mathbf{2}$ & $\mathbf{2}$ & $\mathbf{2}$ & $\mathbf{2}$ \\
$2003-04$ & 22 & 16 & 17 & 15 & $\mathbf{1 6}$ & $\mathbf{1 3}$ & $\mathbf{1 1}$ & $\mathbf{6}$ & $\mathbf{5}$ & $\mathbf{6}$ & $\mathbf{3}$ & $\mathbf{2}$ & $\mathbf{2}$ & $\mathbf{2}$ \\
$2004-05$ & 31 & 23 & 24 & 20 & $\mathbf{1 5}$ & $\mathbf{1 6}$ & $\mathbf{1 7}$ & $\mathbf{1 2}$ & $\mathbf{7}$ & $\mathbf{6}$ & $\mathbf{4}$ & $\mathbf{3}$ & $\mathbf{2}$ & $\mathbf{2}$ \\
$2005-06$ & 47 (42 covered & 33 & 35 & 26 & $\mathbf{2 2}$ & $\mathbf{1 7}$ & $\mathbf{2 6}$ & $\mathbf{1 8}$ & $\mathbf{1 1}$ & $\mathbf{9}$ & $\mathbf{4}$ & $\mathbf{4}$ & $\mathbf{3}$ & $\mathbf{2}$ \\
& by this report) & & & & & & & & & & & & & \\
planned & & & & & & & & & & & & & \\
\end{tabular}

Notes: The table shows the number of New York City charter schools participating in this study and the grades offered by them in each school year. The final row shows the grades that they plan to offer. Bold typeface demarcates grades and years for which we have useful data from statewide tests administered in New York.

Sources: Authors' calculations based on information provided by the charter schools, the New York State Board of Regents, the New York City Basic Educational Data System, and the New York City Center for Charter School Excellence. 
Table 2

Student Applicants by Grade, New York City Charter Schools, All Years through 2005-06

\begin{tabular}{lc}
\hline Grade & Share of Applicants \\
\hline Kindergarten & $31.6 \%$ \\
One & $16.5 \%$ \\
Two & $9.7 \%$ \\
Three & $7.6 \%$ \\
Four & $5.4 \%$ \\
Five & $13.9 \%$ \\
Six & $6.9 \%$ \\
Seven & $2.4 \%$ \\
Eight & $1.0 \%$ \\
Nine & $2.5 \%$ \\
Ten & $1.8 \%$ \\
Eleven & $0.4 \%$ \\
Twelve & $0.2 \%$ \\
\hline
\end{tabular}

Notes: The table shows the percentage of applicants to New York City charter schools who have applied to each grade over the 2000-01 and 2005-06 school years. Charter schools covered by this report are included. Intake grades in New York City charter schools are kindergarten, one, five, and nine. See text for more on the grade spans of the charter schools.

Sources: Authors' calculations based on application data provided by the charter schools. 
Table 3

The Neighborhoods of Charter Schools versus New York City as a Whole Statistics based on Tracts in 2000 U.S. Census of Population and Housing

\begin{tabular}{lcc}
\hline Characteristic & $\begin{array}{c}\text { average tract in which a } \\
\text { charter school is located }\end{array}$ & $\begin{array}{c}\text { average tract in all of } \\
\text { New York City }\end{array}$ \\
\hline \% White (non-Hispanic) & $12.2 \%$ & $35.0 \%$ \\
\% Black (non-Hispanic) & $46.1 \%$ & $24.5 \%$ \\
\% Hispanic & $35.6 \%$ & $27.0 \%$ \\
\% Asian & $2.8 \%$ & $9.7 \%$ \\
Median family income & $\$ 28,993$ & $\$ 41,887$ \\
\% living in poverty & $31.4 \%$ & $21.2 \%$ \\
\% of adults with high school diploma + & $59.6 \%$ & $72.3 \%$ \\
\% of adults with bachelor's degree + & $16.4 \%$ & $27.4 \%$ \\
$\%$ of school-aged children living with a single & & \\
female householder & $39.2 \%$ & $28.8 \%$ \\
\hline
\end{tabular}

Source: Authors' calculations based on Summary File 1 and Summary File 3 of the 2000 Census of Population and Housing. 
Table 4

Policies and Practices of New York City Charter Schools

\begin{tabular}{lcc}
\hline & \multicolumn{2}{c}{ Share of New York City } \\
Policy or practice (2005-06) & Charter School & Charter \\
& Students & Schools \\
\hline Operated by a Charter Management Organization (CMO) & $28.6 \%$ & $18.4 \%$ \\
Operated by an Education Management Organization (EMO) & $16.7 \%$ & $25.3 \%$ \\
Operated by a Community Grown Organization (CGO) & $54.8 \%$ & $56.3 \%$ \\
Long school day (8 hours or more) & $54.8 \%$ & $45.5 \%$ \\
Long school year (190 days or more) & $64.3 \%$ & $57.1 \%$ \\
Optional after-school program available & $66.7 \%$ & $69.0 \%$ \\
Saturday School (mandatory for all or certain students) & $57.1 \%$ & $59.7 \%$ \\
Long English/language arts period (over 90 minutes) & $53.7 \%$ & $55.0 \%$ \\
Long mathematics period (90 minutes or more) & $53.7 \%$ & $54.2 \%$ \\
Saxon Math curriculum & $40.5 \%$ & $36.8 \%$ \\
Everyday Math curriculum & $23.8 \%$ & $32.5 \%$ \\
Open Court Reading curriculum & $23.8 \%$ & $26.5 \%$ \\
Core Knowledge curriculum & $38.1 \%$ & $35.5 \%$ \\
Student-faculty advisory & $38.1 \%$ & $38.8 \%$ \\
Internal assessments regularly administered & $95.1 \%$ & $93.0 \%$ \\
Parent contract & $52.4 \%$ & $48.9 \%$ \\
Seat on the Board of Trustees reserved for a parent & $52.4 \%$ & $58.5 \%$ \\
No Broken Windows disciplinary philosophy & $21.4 \%$ & $13.5 \%$ \\
Uniforms required & $90.5 \%$ & $80.7 \%$ \\
Teachers unionized & $16.7 \%$ & $21.9 \%$ \\
Merit pay or bonuses for teachers & $48.8 \%$ & $50.2 \%$ \\
\hline
\end{tabular}

Notes: More detailed descriptions of these policies may be found in the text.

Source: Authors' calculations based on descriptions provided by the charter schools. Preliminary descriptions were based on charter schools' published materials. These were confirmed, amplified, and corrected by charter school personnel in 2006. 
Table 5

\section{Matching of Charter Schools Applicants to their Records in the New York City Department of Education (DOE) Database, By Year of Intended Entry into Charter School}

\begin{tabular}{|c|c|c|c|c|c|c|}
\hline & \multicolumn{6}{|c|}{ Students who applied in order to enter a charter school in... } \\
\hline & $\begin{array}{c}2005- \\
06\end{array}$ & $\begin{array}{c}2004- \\
05\end{array}$ & $\begin{array}{c}2003- \\
04\end{array}$ & $\begin{array}{c}2002- \\
03\end{array}$ & $\begin{array}{c}2001- \\
02\end{array}$ & $\begin{array}{c}2000- \\
01\end{array}$ \\
\hline $\begin{array}{l}\text { Number of recorded applicants } \\
\text { to charter schools in study }\end{array}$ & 14,301 & 9,610 & 5,523 & 2,957 & 3,238 & 1,613 \\
\hline$\%$ Matched to DOE data & $90.8 \%$ & $88.4 \%$ & $88.7 \%$ & $82.8 \%$ & $79.2 \%$ & $88.0 \%$ \\
\hline $\begin{array}{l}\text { Number of recorded applicants } \\
\text { to charter schools who } \\
\text { participated in lotteries }\end{array}$ & 13,400 & 9,044 & 5,278 & 2,776 & 2,613 & 936 \\
\hline$\%$ Matched to DOE data & $91.1 \%$ & $88.9 \%$ & $88.1 \%$ & $81.7 \%$ & $74.2 \%$ & $79.3 \%$ \\
\hline $\begin{array}{l}\text { Number of students ever } \\
\text { attending a NYC charter } \\
\text { school }^{\text {b }}\end{array}$ & 5,104 & 3,450 & 1,727 & 527 & 1,045 & 1,095 \\
\hline $\begin{array}{l}\text { Number of students who have } \\
\text { attended a NYC charter school } \\
\text { and are in study }\end{array}$ & 4,817 & 3,416 & 1,673 & 527 & 1,045 & 1,095 \\
\hline
\end{tabular}

Notes:

a A "recorded applicant" is a student whose application to a charter school was given to the study for matching into the New York City Basic Educational Data System. Not all students who applied to charter schools are recorded applicants because some charter schools did not keep records of their applicants from years prior to the commencement of the study.

${ }^{\mathrm{b}}$ There are some early years of data for which we are missing enrollment data from certain charter schools because these charter schools had not yet started using the New York City's ATS system for tracking enrollment. These figures also do not include the closed Reisenbach Charter School or the New York Center for Autism Charter School. 
Table 6

Attrition of Student Applicants from the Data, By Enrolled versus Not Enrolled and Lotteried-in versus Lotteried-out

\begin{tabular}{|c|c|c|c|c|c|}
\hline & $\begin{array}{l}\text { Number of } \\
\text { students } \\
\text { who could } \\
\text { attrit }\end{array}$ & $\begin{array}{l}\text { Probability of } \\
\text { attrition among } \\
\text { those enrolled in } \\
\text { a charter school } \\
\end{array}$ & $\begin{array}{l}\text { Increase or decrease in probability } \\
\text { of attrition associated with not } \\
\text { being enrolled [yes/no statistically } \\
\text { significant at } 95 \% \text { level] }\end{array}$ & $\begin{array}{l}\text { Probability of } \\
\text { attrition among } \\
\text { lotteried-in } \\
\text { applicants }\end{array}$ & $\begin{array}{l}\text { Increase or decrease in probability } \\
\text { of attrition associated with being } \\
\text { lotteried-out [yes/no statistically } \\
\text { significant at } 95 \% \text { level] }\end{array}$ \\
\hline All students & 32551 & $0.12 \%$ & $\begin{array}{c}-0.02 \\
{[\mathrm{no}]}\end{array}$ & $0.15 \%$ & $\begin{array}{c}-0.11 \\
{[\mathrm{no}]}\end{array}$ \\
\hline Female & 16022 & $0.11 \%$ & $\begin{array}{c}+0.03 \\
{[\text { no }]}\end{array}$ & $0.17 \%$ & $\begin{array}{r}-0.05 \\
{[\mathrm{no}]}\end{array}$ \\
\hline Black & 20822 & $0.12 \%$ & $\begin{array}{r}-0.10 \\
{[\text { no }]}\end{array}$ & $0.13 \%$ & $\begin{array}{r}-0.09 \\
{[\mathrm{no}]}\end{array}$ \\
\hline White & 1337 & $0.16 \%$ & $\begin{array}{c}+0.00 \\
{[\mathrm{no}]}\end{array}$ & $0.00 \%$ & $\begin{array}{l}0.00 \\
{[\mathrm{no}]}\end{array}$ \\
\hline Hispanic & 8825 & $0.11 \%$ & $\begin{array}{c}+0.14 \\
{[\mathrm{no}]}\end{array}$ & $0.21 \%$ & $\begin{array}{l}-0.20 \\
{[\mathrm{no}]}\end{array}$ \\
\hline Asian & 919 & $0.00 \%$ & $\begin{array}{c}+0.00 \\
{[\text { no }]}\end{array}$ & $0.00 \%$ & $\begin{array}{l}0.00 \\
{[\mathrm{no}]}\end{array}$ \\
\hline Other race & 181 & $0.00 \%$ & $\begin{array}{c}+0.00 \\
{[\mathrm{no}]}\end{array}$ & $0.00 \%$ & $\begin{array}{l}0.00 \\
{[\mathrm{no}]}\end{array}$ \\
\hline $\begin{array}{l}\text { Certified for free } \\
\text { or reduced-price } \\
\text { lunch }\end{array}$ & 27467 & $0.07 \%$ & $\begin{array}{c}-0.01 \\
{[\mathrm{no}]}\end{array}$ & $0.08 \%$ & $\begin{array}{c}-0.05 \\
{[\mathrm{no}]}\end{array}$ \\
\hline $\begin{array}{l}\text { Special education } \\
\text { participant }\end{array}$ & 4541 & $0.06 \%$ & $\begin{array}{l}0.00 \\
{[\mathrm{no}]}\end{array}$ & $0.05 \%$ & $\begin{array}{l}0.00 \\
{[\mathrm{no}]}\end{array}$ \\
\hline $\begin{array}{l}\text { English Language } \\
\text { Learner }\end{array}$ & 2017 & $0.00 \%$ & $\begin{array}{l}0.24 \\
{[\mathrm{no}]}\end{array}$ & $0.12 \%$ & $\begin{array}{r}-0.19 \\
{[\mathrm{no}]}\end{array}$ \\
\hline
\end{tabular}

Notes: A student only has the potential to attrit from the data if he or she has been observed in the data as attending a traditional public school or a charter school for at least two-thirds of an academic year. A student is considered an attritor once he or she has been observed in the dataset for two-thirds of a year or more and then no longer has any attendance data for any of the years afterwards. The two most common reasons a student would attrit from the data is that the student has moved out of New York City or that the student leaves the public school system to attend a private school (or home school). A student who graduates from twelfth grade is not considered an attritor. Source: Authors' calculations based on the New York City Basic Educational Data System and application data. 
Table 7

Gender, Race, and Ethnicity of Charter School Applicants Versus the Traditional Public Schools from Which They Draw Applicants

\begin{tabular}{llrrr}
\hline & & $\begin{array}{r}\text { Applicants to } \\
\text { charter schools }\end{array}$ & $\begin{array}{r}\text { Composite } \\
\text { comparison } \\
\text { school }\end{array}$ & $\begin{array}{r}\text { All New York } \\
\text { City traditional } \\
\text { public school } \\
\text { students }\end{array}$ \\
\hline Most recent & \% female & & $50.17^{\mathrm{b}}$ & $49.15^{\mathrm{c}}$ \\
application year & \% white non-Hispanic & 63.93 & $50.01^{\mathrm{b}}$ & $32.44^{\mathrm{c}}$ \\
$(2005-06)$ & \% Hispanic & 3.63 & $2.30^{\mathrm{b}}$ & $14.35^{\mathrm{c}}$ \\
& \% Asian & 27.03 & $44.89^{\mathrm{b}}$ & $39.20^{\mathrm{c}}$ \\
& \% other race or ethnicity & 3.27 & $2.27^{\mathrm{b}}$ & $13.56^{\mathrm{c}}$ \\
& & 0.51 & 0.52 & 0.45 \\
$2000-01$ to & \% female & & & \\
\% black non-Hispanic & & & \\
application & \% white non-Hispanic & 48.91 & 50.22 & \\
years & \% Asian & 63.46 & $46.83^{\mathrm{b}}$ & $2.47^{\mathrm{b}}$ \\
& \% other race or ethnicity & 3.55 & $47.99^{\mathrm{b}}$ & \\
\hline
\end{tabular}

Notes:

${ }^{a}$ The composite comparison school is a weighted average of traditional New York City public schools from which the charter schools draw applicants. Each school's weight is based on its share of the charter schools' applicants, regardless of their lottery outcome.

${ }^{\mathrm{b}}$ The difference between this number and the parallel number for charter school applicants is statistically significant different from zero at the 99 percent level under the assumption that the charter schools' measured draw from traditional public schools is the true draw. This assumption is strong because lotteried-in kindergarten applicants' traditional public school must be approximated and the error involved in that approximation is unknown. The approximation and the assumption are the reasons why the 99 percent level is used in this table rather than the 95 percent level.

${ }^{c}$ The difference between this number and the parallel number for charter school applicants is statistically significant different from zero at the 95 percent level.

Source: Authors' calculations based on the New York City Basic Educational Data System and application data. 
Table 8

Proxies for Poverty, Disability, and Need to Learn English ${ }^{\text {a }}$,

Charter School Applicants and the Traditional Public Schools from Which They Draw Applicants

\author{
Comparison of applicants \\ average grade of intended entry (kindergarten $=0$ ) \\ $\%$ female \\ $\%$ black non-Hispanic \\ $\%$ white non-Hispanic \\ $\%$ Hispanic \\ $\%$ Asian \\ $\%$ other race or ethnicity
} applicants for whom time-of application proxies...

are available
3.74
49.66
61.45
3.34
31.49
2.27
0.49

2005 charter school applicants for whom time-of-application proxies are available.

\begin{tabular}{rr}
3.74 & $1.91^{\mathrm{b}}$ \\
49.66 & $48.72^{\mathrm{b}}$ \\
61.45 & $65.43^{\mathrm{b}}$ \\
3.34 & $4.77^{\mathrm{b}}$ \\
31.49 & $23.39^{\mathrm{b}}$ \\
2.27 & $3.15^{\mathrm{b}}$ \\
0.49 & $0.63^{\mathrm{b}}$ \\
\hline
\end{tabular}

$\begin{array}{cc}\text { Composite } & \text { All New York City } \\ \text { comparison }^{\text {school }} & \text { public school } \\ \text { scho }^{\mathrm{c}} & \text { students }\end{array}$

\section{Proxies at time of application}

Certified for free or reduced-price lunch Participating in special education Classified as an English Language Learner unadjusted

$$
\begin{array}{r}
91.06^{\mathrm{d}} \\
8.07^{\mathrm{d}} \\
2.57^{\mathrm{d}}
\end{array}
$$

adjusted to create same grade composition as traditional public schools
$93.00^{\mathrm{d}}$

\section{Notes:}

${ }^{a}$ The proxies for poverty, disability, and the need to learn English are, respectively, certification for free or reduced-price lunch, participation in special education, and classification as an English Language Learner. The variables are proxies because they measure the treatment a student receives rather than his circumstances.

b The difference between this number and the parallel number for applicants whose time-of-application data are available is statistically significant different from zero at the 95 percent level.

${ }^{\mathrm{c}}$ The composite comparison school is a weighted average of traditional New York City public schools from which the charter schools draw applicants. Each school's weight is based on its share of the charter schools' applicants, regardless of their lottery outcome. Unfortunately, the composite comparison school shown in this table does not have the same grade composition as the applicants. This is unlike the previous table. These and New York City numbers are for 2005-06.

${ }^{d}$ This number is reliable in the sense of having been recorded for all schools in the table by the New York City traditional public schools. However, this number is not representative of applicants to New York City charter schools. 
Table 9

Prior Test Scores, Charter School Applicants and the Traditional Public Schools from Which They Draw Applicants

\begin{tabular}{|c|c|c|c|c|}
\hline \multirow{2}{*}{\multicolumn{3}{|c|}{ Comparison of applicants }} & \multicolumn{2}{|c|}{ Applicants for whom prior test scores... } \\
\hline & & & \multirow{2}{*}{$\begin{array}{r}\text { are available } \\
5.65\end{array}$} & are not available \\
\hline \multicolumn{3}{|c|}{ average grade of intended entry (kindergarten $=0$ ) } & & \multirow{2}{*}{$\begin{array}{r}1.89^{\mathrm{a}} \\
4870^{\mathrm{a}}\end{array}$} \\
\hline \multicolumn{3}{|c|}{$\%$ female } & 50.72 & \\
\hline \multicolumn{3}{|c|}{$\%$ black non-Hispanic } & 55.50 & $66.06^{\mathrm{a}}$ \\
\hline \multicolumn{3}{|c|}{$\%$ white non-Hispanic } & 3.47 & $4.25^{\mathrm{a}}$ \\
\hline \multicolumn{3}{|c|}{$\%$ Hispanic } & 36.98 & $24.25^{\mathrm{a}}$ \\
\hline \multicolumn{3}{|l|}{$\%$ Asian } & 3.13 & $2.59^{\mathrm{a}}$ \\
\hline \multicolumn{3}{|c|}{$\%$ other race or ethnicity } & 0.57 & 0.56 \\
\hline \multirow{7}{*}{$\begin{array}{l}\text { Math } \\
\text { Standard Score } \\
\text { grade at time } \\
\text { of application }\end{array}$} & & $\begin{array}{c}\text { Applicants for whom prior test scores are available }{ }^{\mathrm{c}} \\
\text { not representative of applicants }\end{array}$ & $\begin{array}{c}\text { Composite comparison } \\
\text { school }^{\mathrm{d}, \mathrm{e}}\end{array}$ & $\begin{array}{l}\text { All New York City public } \\
\text { school students }^{\mathrm{e}}\end{array}$ \\
\hline & grade 3 & -0.102 & -0.336 & 0 \\
\hline & grade 4 & 0.016 & -0.236 & 0 \\
\hline & grade 5 & -0.009 & -0.306 & 0 \\
\hline & grade 6 & -0.004 & -0.126 & 0 \\
\hline & grade 7 & -0.250 & -0.198 & 0 \\
\hline & grade 8 & -0.001 & -0.253 & 0 \\
\hline \multirow{6}{*}{$\begin{array}{l}\text { Reading } \\
\text { Standard Score } \\
\text { grade at time } \\
\text { of application }\end{array}$} & grade 3 & -0.125 & -0.347 & 0 \\
\hline & grade 4 & 0.014 & -0.257 & 0 \\
\hline & grade 5 & -0.003 & -0.304 & 0 \\
\hline & grade 6 & 0.047 & -0.174 & 0 \\
\hline & grade 7 & -0.100 & -0.259 & 0 \\
\hline & grade 8 & -0.100 & -0.276 & 0 \\
\hline
\end{tabular}

Notes:

a The difference between this number and the parallel number for applicants whose prior test scores are available is statistically significant different from zero at the 95 percent level.

${ }^{\mathrm{b}}$ A standard score is the equal to the difference between the scale score and the New York City-wide mean divided by the New York City-wide standard deviation. The city-wide means and standard deviations are specific to the grade and year.

${ }^{c}$ Students who applied to charter schools in 2001 through 2005 . We do not include the 2000 applicants to avoid conversion school entrants who were admitted in pre-conversion days.

${ }^{\mathrm{d}}$ The composite comparison school is a weighted average of traditional New York City public schools from which the charter schools draw applicants. Each school's weight is based on its share of the charter schools' applicants, regardless of their lottery outcome.

${ }^{\mathrm{e}}$ Scores from 2004-05, the prior year for the modal applicant. However, all scores are standardized so the year should not matter much. 
Table 10

Predetermined Characteristics of Applicants to Charter Schools

\begin{tabular}{|c|c|c|c|c|c|c|c|c|}
\hline & \multicolumn{4}{|c|}{ All applicants who participated in lotteries } & \multicolumn{4}{|c|}{ Applicants who participated in balanced lotteries } \\
\hline & $\begin{array}{r}\text { Lotteried-in } \\
\text { applicants }\end{array}$ & $\begin{array}{r}\text { Compliers } \\
\text { are this } \\
\text { much } \\
\text { above/ } \\
\text { below } \\
\text { average } \\
\text { lotteried-in } \\
\text { applicant }\end{array}$ & $\begin{array}{r}\text { Decliners } \\
\text { are this } \\
\text { much } \\
\text { above/ } \\
\text { below } \\
\text { average } \\
\text { lotteried- } \\
\text { in } \\
\text { applicant }\end{array}$ & $\begin{array}{r}\text { Lotteried- } \\
\text { out are this } \\
\text { much } \\
\text { above/ } \\
\text { below } \\
\text { lotteried-In }\end{array}$ & $\begin{array}{r}\text { Balanced } \\
\text { lotteried-in } \\
\text { are this } \\
\text { much } \\
\text { above/ } \\
\text { below } \\
\text { average } \\
\text { lotteried-in } \\
\text { applicant }\end{array}$ & $\begin{array}{r}\text { Compliers } \\
\text { are this } \\
\text { much } \\
\text { above/ } \\
\text { below } \\
\text { average } \\
\text { balanced } \\
\text { lotteried-in } \\
\text { applicant }\end{array}$ & $\begin{array}{r}\text { Decliners } \\
\text { are this } \\
\text { much } \\
\text { above/ } \\
\text { below } \\
\text { average } \\
\text { balanced } \\
\text { lotteried-in } \\
\text { applicant }\end{array}$ & $\begin{array}{r}\text { Balanced } \\
\text { lotteried- } \\
\text { out are this } \\
\text { much } \\
\text { above/belo } \\
\text { w balanced } \\
\text { lotteried-In }\end{array}$ \\
\hline$\%$ female & 50.05 & $1.06^{\mathrm{a}}$ & $-0.44^{\mathrm{b}}$ & -0.75 & 0.03 & $1.65^{\mathrm{a}}$ & $-0.80^{\mathrm{b}}$ & -0.99 \\
\hline$\%$ black non-hispanic & 63.51 & 0.00 & -0.18 & 0.04 & 1.99 & 0.39 & -0.17 & -0.24 \\
\hline$\%$ white non-hispanic & 4.17 & -0.20 & 0.18 & 0.11 & -0.99 & -0.24 & 0.17 & 0.13 \\
\hline$\%$ hispanic & 26.98 & -0.04 & 0.51 & -0.10 & -0.66 & -0.25 & 0.05 & 0.17 \\
\hline$\%$ asian & 2.84 & 0.16 & -0.44 & -0.01 & -0.58 & 0.07 & 0.01 & -0.06 \\
\hline$\%$ other & 0.52 & -0.06 & 0.11 & 0.02 & -0.01 & -0.09 & 0.13 & 0.03 \\
\hline $\begin{array}{l}\text { age at the time of } \\
\text { application }\end{array}$ & 8.42 & -0.02 & -0.05 & 0.04 & -0.75 & -0.01 & -0.03 & 0.02 \\
\hline $\begin{array}{l}\% \text { certificated for free } \\
\text { or reduced-price lunch }\end{array}$ & 89.68 & 0.01 & -0.25 & 0.06 & 0.73 & 0.16 & 0.02 & -0.11 \\
\hline $\begin{array}{l}\% \text { participate in special } \\
\text { education }\end{array}$ & 7.61 & $-0.58^{\mathrm{a}}$ & $0.87^{\mathrm{a}, \mathrm{b}}$ & 0.31 & -0.45 & $-0.82^{\mathrm{a}}$ & $0.96^{\mathrm{a}, \mathrm{b}}$ & 0.32 \\
\hline $\begin{array}{l}\text { \% classified as english } \\
\text { language learners }\end{array}$ & 2.03 & -0.20 & $0.37^{\mathrm{b}}$ & 0.09 & 0.26 & -0.31 & $0.56^{\mathrm{b}}$ & 0.06 \\
\hline math standard score & 0.0075 & 0.0181 & 0.0189 & -0.0214 & 0.0158 & 0.0357 & -0.0097 & -0.0222 \\
\hline reading standard score & 0.0073 & 0.0115 & 0.0369 & -0.0200 & 0.0004 & 0.0296 & 0.0114 & -0.0228 \\
\hline
\end{tabular}

Notes:

The table shows the pre-lottery characteristics of students who are lotteried, who are lotteried-in and enroll in a charter school (compliers), who are lotteried and do not enroll in a charter school (decliners), and who are lotteried-out. Lottery fixed effects are removed before the differences shown in the table are computed. The following number of observations are in the columns, left to right: 20501, 15497, 5004, 18945, 11037, 7812, 3225, 10384. Source: Authors' calculations based on the New York City Basic Educational Data System and application data.

${ }^{a}$ Difference is statistically significantly difference from zero at the 95 percent level.

${ }^{\mathrm{b}}$ Difference between decliners and compliers is statistically significantly difference from zero at the 95 percent level. 
Table 11

Number of Students Available for Assessing

the Achievement Effects of New York City's Charter Schools (Number of Test-Taking Students Who Participated in Balanced Lotteries)

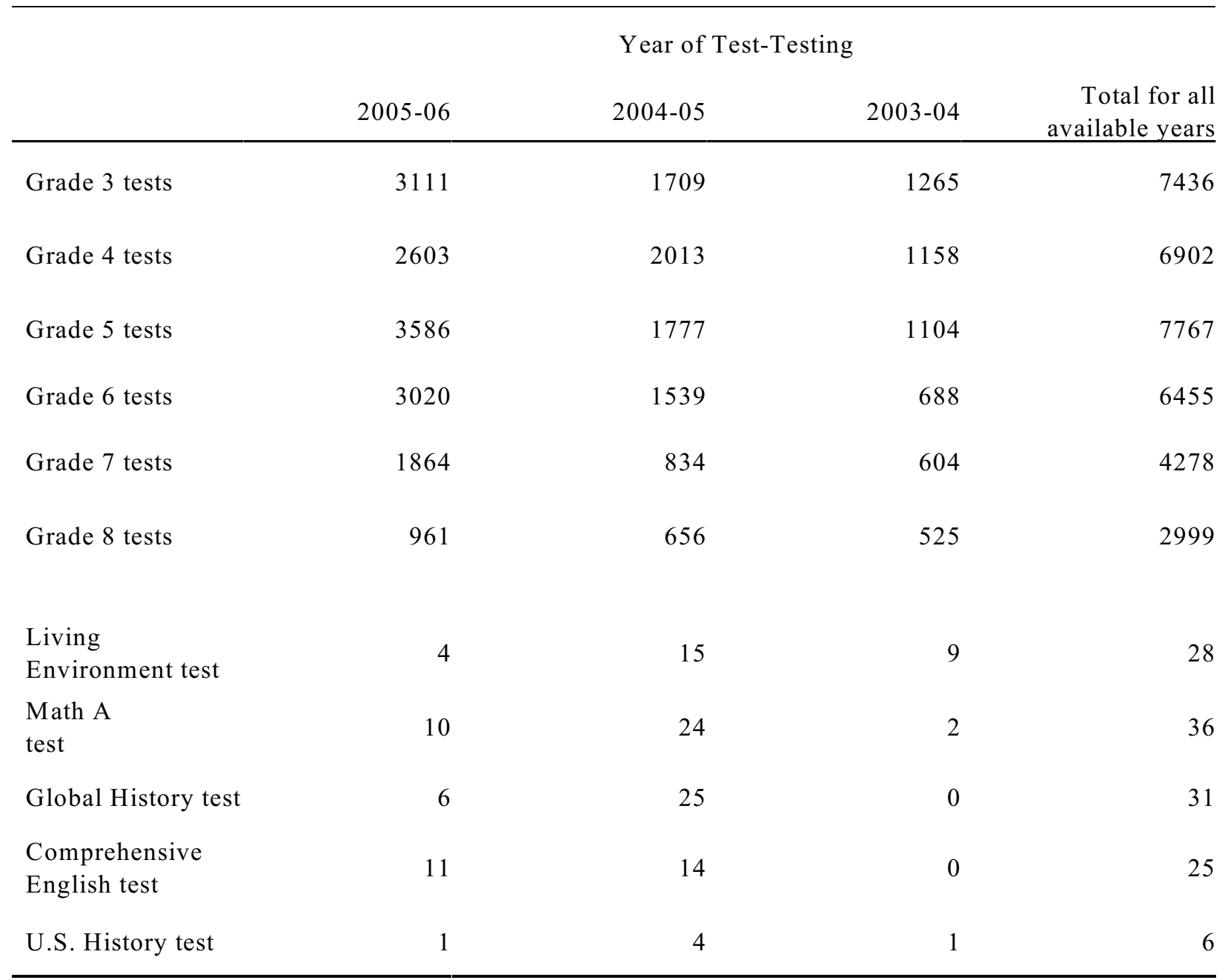

Notes: The table shows the number of test-taking students in each year who participated in balanced lotteries held by New York City charter schools. The "All Available" column contains the total number of students over the school years available currently from New York City Basic Educational Data System: 2000-01 to 2005-06. A school will have no balanced lottery available if it held no lottery among applicants, if it failed to keep full application information on lotteried-out students, or if the number of participants in the lottery was so small that the lotteried-in and lotteried-out groups were statistically significantly different at the 90 percent level. In the years before this study commenced, many schools failed to keep full application information on lotteried-out students simply because they were unaware that such information might later be needed.

Source: Authors' calculations based on the New York City Basic Educational Data System and application data. 
Table 12

\section{Lottery-Based Estimates of the Effect of Attending New York City's Charter Schools, Per Year of Attendance, on Math Test Scores for Grades 3 through 8}

\begin{tabular}{|c|c|c|c|c|c|c|c|c|}
\hline \multirow[b]{2}{*}{$\begin{array}{l}\text { years enrolled in } \\
\text { charter school }\end{array}$} & \multicolumn{8}{|c|}{ Estimated Effect of Attending New York City's Charter Schools, Per Year of Attendance, on Math } \\
\hline & $\begin{array}{c}0.092 \\
(0.016) \\
{[<0.001]}\end{array}$ & $\begin{array}{c}0.113 \\
(0.017) \\
{[<0.001]}\end{array}$ & $\begin{array}{c}0.094 \\
(0.016) \\
{[<0.001]}\end{array}$ & $\begin{array}{c}0.113 \\
(0.017) \\
{[<0.001]}\end{array}$ & $\begin{array}{c}0.100 \\
(0.016) \\
{[<0.001]}\end{array}$ & $\begin{array}{c}0.097 \\
(0.016) \\
{[<0.001]}\end{array}$ & $\begin{array}{c}0.092 \\
(0.016) \\
{[<0.001]}\end{array}$ & $\begin{array}{c}0.059 \\
(0.012) \\
{[<0.001]}\end{array}$ \\
\hline $\begin{array}{l}\text { treatment on the } \\
\text { treated results }\end{array}$ & yes & yes & yes & yes & yes & yes & yes & yes \\
\hline $\begin{array}{l}\text { results based on } \\
\text { balanced lotteries } \\
\text { results based on all }\end{array}$ & yes & yes & yes & yes & yes & yes & yes & \\
\hline $\begin{array}{l}\text { lotteries regardless of } \\
\text { balance }\end{array}$ & & & & & & & & yes \\
\hline $\begin{array}{l}\text { gender, race, and } \\
\text { ethnicity covariates } \\
\text { free and reduced } \\
\text { lunch, special }\end{array}$ & yes & yes & yes & yes & & yes & yes & \\
\hline $\begin{array}{l}\text { education, and } \\
\text { English learner } \\
\text { covariates }\end{array}$ & yes & yes & & & & yes & yes & \\
\hline $\begin{array}{l}\text { prior test score } \\
\text { covariates }\end{array}$ & yes & & yes & & yes & yes & yes & yes \\
\hline $\begin{array}{l}\text { grade of test fixed } \\
\text { effects }\end{array}$ & yes & yes & yes & yes & yes & yes & yes & yes \\
\hline $\begin{array}{l}\text { school year fixed } \\
\text { effects }\end{array}$ & yes & yes & yes & yes & yes & yes & yes & yes \\
\hline $\begin{array}{l}\text { lottery fixed effects } \\
\text { siblings excluded }\end{array}$ & yes & yes & yes & yes & yes & yes & yes & yes \\
\hline $\begin{array}{l}\text { even if in balanced } \\
\text { lotteries }\end{array}$ & & & & & & yes & & \\
\hline $\begin{array}{l}\text { reweighting } \\
\text { correction for attrition }\end{array}$ & & & & & & & yes & \\
\hline $\begin{array}{l}\text { robust standard error } \\
\text { clustered at the } \\
\text { student level }\end{array}$ & yes & yes & yes & yes & yes & yes & yes & yes \\
\hline
\end{tabular}

Notes: The table shows the effect of attending New York City's charter schools per school year. Robust clustered standard errors, computed using Stata's "robust cluster" command are in parentheses and p-values are in square brackets. The effects shown are treatment on the treated estimates; that is, the intention-to-treat variable described in the text is used as an instrument time enrolled in a charter school.

Sources: Authors' calculations based on data from the New York City Basic Educational Data System and application data from charter schools. 
Table 13

\section{Lottery-Based Estimates of the Effect of Attending New York City's Charter Schools, Per Year of Attendance, on Reading Test Scores for Grades 3 through 8}

\begin{tabular}{|c|c|c|c|c|c|c|c|c|}
\hline \multirow[b]{2}{*}{$\begin{array}{l}\text { years enrolled in } \\
\text { charter school }\end{array}$} & \multicolumn{3}{|c|}{ Estimated Effect of Attending New } & \multicolumn{2}{|c|}{ York City's Charter Schools } & \multicolumn{3}{|c|}{ Per Year of Attendance, on Reading } \\
\hline & $\begin{array}{c}0.039 \\
(0.016) \\
{[0.016]}\end{array}$ & $\begin{array}{c}0.065 \\
(0.018) \\
{[<0.001]}\end{array}$ & $\begin{array}{c}0.041 \\
(0.016) \\
{[0.011]}\end{array}$ & $\begin{array}{c}0.068 \\
(0.018) \\
{[<0.001]}\end{array}$ & $\begin{array}{c}0.050 \\
(0.016) \\
{[0.003]}\end{array}$ & $\begin{array}{c}0.042 \\
(0.016) \\
{[0.011]}\end{array}$ & $\begin{array}{c}0.039 \\
(0.016) \\
{[0.016]}\end{array}$ & $\begin{array}{c}0.042 \\
(0.013) \\
{[0.001]}\end{array}$ \\
\hline $\begin{array}{l}\text { treatment on the } \\
\text { treated results }\end{array}$ & yes & yes & yes & yes & yes & yes & yes & yes \\
\hline $\begin{array}{l}\text { results based on } \\
\text { balanced lotteries } \\
\text { results based on all }\end{array}$ & yes & yes & yes & yes & yes & yes & yes & \\
\hline $\begin{array}{l}\text { lotteries regardless of } \\
\text { balance }\end{array}$ & & & & & & & & yes \\
\hline $\begin{array}{l}\text { gender, race, and } \\
\text { ethnicity covariates } \\
\text { free and reduced } \\
\text { lunch, special }\end{array}$ & yes & yes & yes & yes & & yes & yes & \\
\hline $\begin{array}{l}\text { education, and } \\
\text { English learner } \\
\text { covariates }\end{array}$ & yes & yes & & & & yes & yes & \\
\hline $\begin{array}{l}\text { prior test score } \\
\text { covariates }\end{array}$ & yes & & yes & & yes & yes & yes & yes \\
\hline $\begin{array}{l}\text { grade of test fixed } \\
\text { effects }\end{array}$ & yes & yes & yes & yes & yes & yes & yes & yes \\
\hline $\begin{array}{l}\text { school year fixed } \\
\text { effects }\end{array}$ & yes & yes & yes & yes & yes & yes & yes & yes \\
\hline $\begin{array}{l}\text { lottery fixed effects } \\
\text { siblings excluded }\end{array}$ & yes & yes & yes & yes & yes & yes & yes & yes \\
\hline $\begin{array}{l}\text { even if in balanced } \\
\text { lotteries }\end{array}$ & & & & & & yes & & \\
\hline $\begin{array}{l}\text { reweighting } \\
\text { correction for attrition }\end{array}$ & & & & & & & yes & \\
\hline $\begin{array}{l}\text { robust standard error } \\
\text { clustered at the } \\
\text { student level }\end{array}$ & yes & yes & yes & yes & yes & yes & yes & yes \\
\hline
\end{tabular}

Notes: The table shows the effect of attending New York City's charter schools per school year. Robust clustered standard errors, computed using Stata's "robust cluster" command are in parentheses and p-values are in square brackets. The effects shown are treatment on the treated estimates; that is, the intention-to-treat variable described in the text is used as an instrument time enrolled in a charter school.

Sources: Authors' calculations based on data from the New York City Basic Educational Data System and application data from charter schools. 
Table 14

Gender and Race/Ethnicity Breakdowns of Lottery-Based Estimates of the Effect of Attending New York City's Charter Schools,
Per Year of Attendance, on Math and Reading Test Scores for Grades 3 through 8

\begin{tabular}{|c|c|c|c|c|c|c|c|c|}
\hline \multirow[b]{3}{*}{$\begin{array}{l}\text { years enrolled in } \\
\text { charter school }\end{array}$} & \multicolumn{4}{|c|}{$\begin{array}{c}\text { Estimated Effect of Attending New York City's } \\
\text { Charter Schools, Per Year of Attendance, } \\
\text { on Math } \\
\text { student is... }\end{array}$} & \multicolumn{4}{|c|}{$\begin{array}{c}\text { Estimated Effect of Attending New York City's } \\
\text { Charter Schools, Per Year of Attendance, } \\
\text { on Reading } \\
\text { student is... }\end{array}$} \\
\hline & male & female & black & Hispanic & male & female & black & Hispanic \\
\hline & $\begin{array}{c}0.091 \\
(0.019) \\
\lceil<0.001]\end{array}$ & $\begin{array}{c}0.093 \\
(0.018) \\
{[<0.001]}\end{array}$ & $\begin{array}{c}0.089 \\
(0.018) \\
{[<0.001]}\end{array}$ & $\begin{array}{c}0.083 \\
(0.019) \\
{[<0.001]}\end{array}$ & $\begin{array}{c}0.025 \\
(0.019) \\
{[0.20]}\end{array}$ & $\begin{array}{l}0.052 \\
(0.018) \\
{[0.004]}\end{array}$ & $\begin{array}{c}0.036 \\
(0.019) \\
{[0.050]}\end{array}$ & $\begin{array}{c}0.031 \\
(0.019) \\
{[0.113]}\end{array}$ \\
\hline $\begin{array}{l}\text { treatment on the } \\
\text { treated results }\end{array}$ & yes & yes & yes & yes & yes & yes & yes & yes \\
\hline $\begin{array}{l}\text { results based on } \\
\text { balanced lotteries }\end{array}$ & yes & yes & yes & yes & yes & yes & yes & yes \\
\hline $\begin{array}{l}\text { gender, race, and } \\
\text { ethnicity covariates } \\
\text { free and reduced } \\
\text { lunch, special }\end{array}$ & yes & yes & yes & yes & yes & yes & yes & yes \\
\hline $\begin{array}{l}\text { education, and } \\
\text { English learner } \\
\text { covariates }\end{array}$ & yes & yes & yes & yes & yes & yes & yes & yes \\
\hline $\begin{array}{l}\text { prior test score } \\
\text { covariates }\end{array}$ & yes & yes & yes & yes & yes & yes & yes & yes \\
\hline $\begin{array}{l}\text { grade of test fixed } \\
\text { effects }\end{array}$ & yes & yes & yes & yes & yes & yes & yes & yes \\
\hline $\begin{array}{l}\text { school year fixed } \\
\text { effects }\end{array}$ & yes & yes & yes & yes & yes & yes & yes & yes \\
\hline lottery fixed effects & yes & yes & yes & yes & yes & yes & yes & yes \\
\hline $\begin{array}{l}\text { robust standard error } \\
\text { clustered at the } \\
\text { student level }\end{array}$ & yes & yes & yes & yes & yes & yes & yes & yes \\
\hline
\end{tabular}

Notes: The table shows the effect of attending New York City's charter schools per school year. Robust clustered standard errors, computed using Stata's "robust cluster" command are in parentheses and p-values are in square brackets. The effects shown are treatment on the treated estimates; that is, the intention-to-treat variable described in the text is used as an instrument time enrolled in a charter school.

Sources: Authors' calculations based on data from the New York City Basic Educational Data System and application data from charter schools. 
Table 15

Lottery-Based Estimates of the Effect of Attending New York City's Charter Schools, Per Year of Attendance, on Regents Examinations (scale points, not standard scores)

\begin{tabular}{|c|c|c|c|c|c|}
\hline & \multicolumn{5}{|c|}{$\begin{array}{c}\text { Estimated Effect of Attending New York City's Charter Schools, Per Year of Attendance, } \\
\text { on Various Regents Examinations }\end{array}$} \\
\hline & $\begin{array}{c}\text { Living } \\
\text { Environment } \\
\end{array}$ & Math A & Global History & $\begin{array}{l}\text { Comprehensive } \\
\text { English }\end{array}$ & U.S. History \\
\hline years enrolled in charter school & $\begin{array}{l}\text { no estimate } \\
\text { available }\end{array}$ & $\begin{array}{l}1.846 \\
(5.924) \\
{[0.757]}\end{array}$ & $\begin{array}{l}\text { no estimate } \\
\text { available }\end{array}$ & $\begin{array}{l}\text { no estimate } \\
\text { available }\end{array}$ & $\begin{array}{l}\text { no estimate } \\
\text { available }\end{array}$ \\
\hline treatment on the treated results & yes & yes & yes & yes & yes \\
\hline $\begin{array}{l}\text { results based on balanced } \\
\text { lotteries }\end{array}$ & yes & yes & yes & yes & yes \\
\hline $\begin{array}{l}\text { gender, race, and ethnicity } \\
\text { covariates }\end{array}$ & yes & yes & yes & yes & yes \\
\hline $\begin{array}{l}\text { free and reduced lunch, special } \\
\text { education, and English learner } \\
\text { covariates }\end{array}$ & yes & yes & yes & yes & yes \\
\hline prior test score covariates & yes & yes & yes & yes & yes \\
\hline grade of test fixed effects & yes & yes & yes & yes & yes \\
\hline school year fixed effects & yes & yes & yes & yes & yes \\
\hline lottery fixed effects & yes & yes & yes & yes & yes \\
\hline $\begin{array}{l}\text { robust standard error clustered at } \\
\text { the student level }\end{array}$ & yes & yes & yes & yes & yes \\
\hline
\end{tabular}

Notes: The table shows the effect of attending New York City's charter schools per school year. Robust clustered standard errors, computed using Stata's "robust cluster" command are in parentheses and p-values are in square brackets. The effects shown are treatment on the treated estimates; that is, the intention-to-treat variable described in the text is used as an instrument time enrolled in a charter school.

Sources: Authors' calculations based on data from the New York City Basic Educational Data System and application data from charter schools. 
Table 16

Associations between Charter Schools' Characteristics and their Estimated Effects on Math and Reading Achievement

\begin{tabular}{|c|c|c|c|}
\hline Characteristic & $\begin{array}{l}\text { Average level of } \\
\text { this characteristic } \\
\text { among New York } \\
\text { City charter } \\
\text { schools }\end{array}$ & regression coefficient & p-value \\
\hline Years that School has been Operating & 3.8 & -0.009 & 0.586 \\
\hline $\begin{array}{l}\text { Community Grown Organization } \\
\text { (CGO) }\end{array}$ & $55 \%$ & -3.690 & 0.112 \\
\hline $\begin{array}{l}\text { Operating Charter Management } \\
\text { Agency is a Organization (CMO) }\end{array}$ & $29 \%$ & -3.660 & 0.147 \\
\hline $\begin{array}{l}\text { Educational Management } \\
\text { Organization (EMO) }\end{array}$ & $17 \%$ & -3.115 & 0.189 \\
\hline Number of Days in School Year & 192.9 & 0.021 & 0.007 \\
\hline Number of Hours in School Day & 7.9 & -0.077 & 0.602 \\
\hline Saturday School & $57 \%$ & 0.153 & 0.549 \\
\hline Optional After-School Program & $64 \%$ & 0.058 & 0.839 \\
\hline $\begin{array}{ll}\text { Math } & \text { Saxon } \\
\text { curriculum is } & \text { Scott Foresman } \\
\text { Everyday }\end{array}$ & $\begin{array}{c}40 \% \\
5 \% \\
21 \%\end{array}$ & $\begin{array}{c}0.180 \\
0.087 \\
-0.332\end{array}$ & $\begin{array}{l}0.507 \\
0.789 \\
0.008\end{array}$ \\
\hline $\begin{array}{ll} & \text { SRA } \\
\text { Reading } & \text { Scott Foresman } \\
\text { curriculum isOpen Court } & \text { Core Knowledge } \\
& \text { Core }\end{array}$ & $\begin{array}{l}12 \% \\
14 \% \\
24 \% \\
38 \%\end{array}$ & $\begin{array}{c}-0.423 \\
-0.174 \\
-0.378 \\
0.072\end{array}$ & $\begin{array}{l}0.188 \\
0.158 \\
0.010 \\
0.592\end{array}$ \\
\hline School's Own Math \& Reading Curricula & $29 \%$ & 0.137 & 0.778 \\
\hline Average Class Size & 23.6 & 0.002 & 0.950 \\
\hline Internal Evaluations Administered & $95 \%$ & -0.085 & 0.836 \\
\hline School Uniforms Required & $88 \%$ & -0.179 & 0.774 \\
\hline Dress Code (with or without uniforms) & $90 \%$ & 0.139 & 0.835 \\
\hline No Broken Windows Disciplinary Policy & $21 \%$ & 0.257 & 0.498 \\
\hline Parent Contract & $50 \%$ & -0.234 & 0.367 \\
\hline Reserved Seat(s) for Parent on Board & $52 \%$ & 0.233 & 0.116 \\
\hline Number of School Leaders & 1.3 & 0.199 & 0.163 \\
\hline
\end{tabular}

Notes: Table shows results from a multivariate regression of charter schools' estimated achievement effects on their characteristics and test subject indicator. Observations are weighted by the precision (inverse of the variance) of the charter school's estimated effect. The p-value for the test that the coefficient is equal to zero is shown in the right-hand column. 


\section{Appendix}

\section{A. Descriptions of curricula}

Saxon Math

Using Saxon Math Courses 1, 2, and 3 each day, students work toward mastery in three ways: by reviewing, maintaining and building upon previously learned skills; through direct, explicit instruction of new content, mathematical thinking and vocabulary; and by applying, reinforcing and demonstrating cumulative learning. Source: http://www.harcourtachieve.com (accessed June 2007).

\section{Scott Foresman-Wesley Addison Mathematics}

Scott Foresman-Addison Wesley Mathematics (Diamond Edition) is a research-based Pre-K-6 curriculum that focuses on developing students' conceptual understanding and skills through step-by-step instruction. The focus is on key ideas in mathematics, rich problem-solving lessons that build the reading and writing skills necessary for powerful problem solving, and differentiated instructional options to meet the needs of varied learners.

Source: http://www.scottforesman.com (accessed June 2007).

\section{Everyday Mathematics}

Everyday Mathematics is a research-based curriculum developed by the University of Chicago School Mathematics Project. Development of Everyday Mathematics began with a research phase. Based on their findings, the authors established several basic principles that have guided the development of Everyday Mathematics: Students acquire knowledge and skills, and develop an understanding of mathematics from their own experience; children begin school with more mathematical knowledge and intuition than previously believed; teachers, and their ability to provide excellent instruction, are the key factors in the success of any program.

Source: http://everydaymath.uchicago.edu/about.shtml (accessed June 2007).

\section{SRA Reading Mastery Plus}

Reading Mastery Plus gives students the skills and the clear, explicit instruction and guidance they need to master the fundamentals of reading. Oral language, phonemic awareness, and systematic phonics are the starting point. Vocabulary development, fluency, and comprehension are fundamental throughout. The program is set up so students are active participants. Group responses make learning highly efficient and enable teachers to provide instant feedback that confirms or corrects their responses. Less-structured activities and opportunities for independent work help students develop self-reliance. On-going assessment tools are used by the instructor to ensure that no student "falls though the cracks."

Source: www.sraonline.com (accessed June 2007).

\section{Scott Foresman Reading Street}

Scott Foresman Reading Street 2008 is an all-new reading program for Grades PreK-6. Reading Street is designed to help teachers build readers through motivating and engaging literature, scientifically research-based instruction, and a wealth of reliable teaching tools. The program takes the guesswork out of differentiating instruction with a strong emphasis on ongoing progress-monitoring and an explicit plan to help with managing small groups of students. In addition, Reading Street prioritizes skill instruction at each grade level, so teachers can be assured they will focus on the right skill, at the right time, and for every student. Source: http://www.scottforesman.com (accessed June 2007).

\section{Open Court Reading}

Open Court Reading is a complete elementary basal reading program for Grades K-6. It maintains strong instruction in the areas of decoding (learning how to read), comprehension (understanding what you read), inquiry and investigation (learning how to apply what you have read), and writing (how to communicate with 
others in print). Open Court Reading is designed such that no assumptions are made about students' prior knowledge. Each skill is systematically and explicitly taught in a logical progression to develop understanding and mastery.

Source: www.sraonline.com (accessed June 2007).

Core Knowledge Reading

Core Knowledge does not at present require any particular reading program. Schools are free to select from programs on the market. However, we recommend that schools choose a program that has strong phonics instruction, and we recommend that schools build oral language through frequent reading aloud on topics in the Core Knowledge Sequence. An ideal reading program will include good phonics instruction (followed by fluency work) combined with frequent reading aloud to expose children to new words and key subjects like the subjects listed in the Core Knowledge Sequence. Moreover, the reading aloud will include not only fictional stories but also generous amounts of nonfiction.

Source: www.coreknowledge.org (accessed June 2007). 
Appendix Figure 1

Relationship between Scale Scores and Performance Levels,

Math 2006

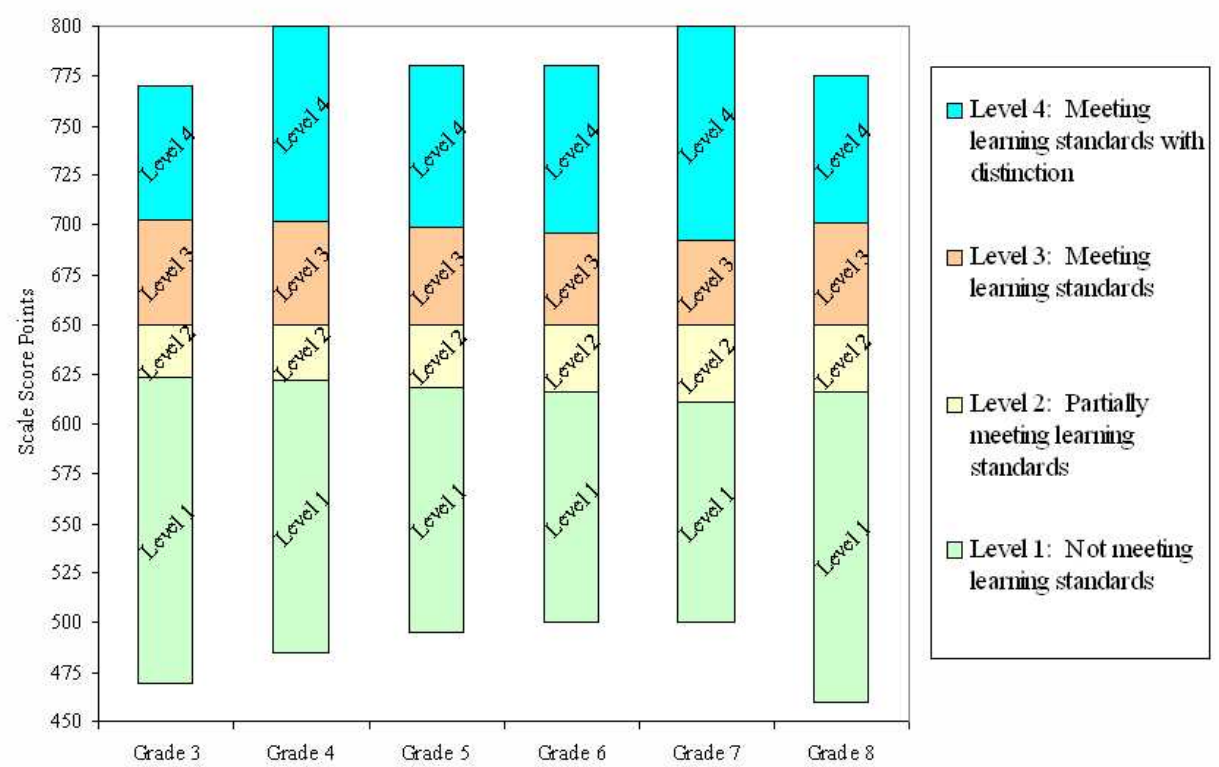

Results of the New York state math assessments are reported as Scaled Scores and Performance Levels. Scaled Scores are the number of correct answers converted to a common scale so that achievement can be compared across grade levels. Performance Levels are four proficiency levels that show how students have mastered the knowledge and skills that make up the learning standards

Source: New York City Department of Education, "Scaled Score and Performance Levels," report posted online at http.//schools.nyc.gov/daal.

Appendix Figure 2

Relationship between Scale Scores and Performance Levels,

English/Language Arts 2006

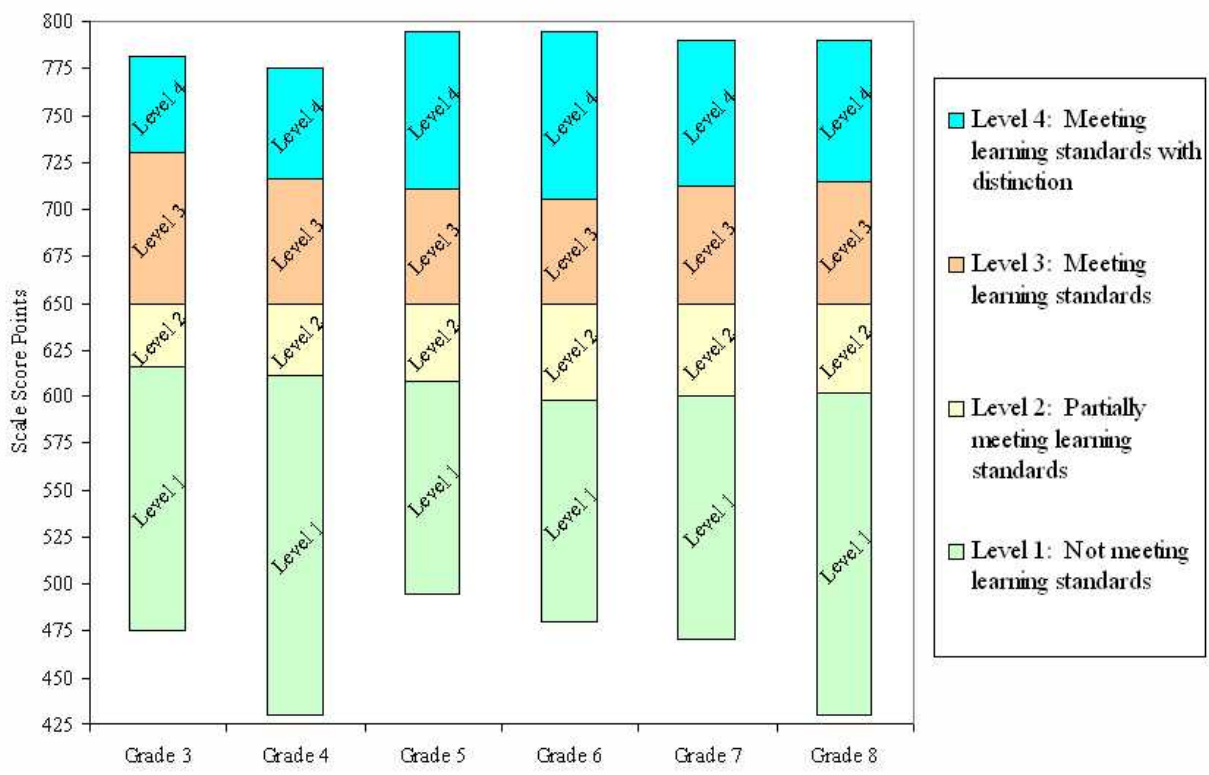

Results of the New York state English/language arts assessments are reported as Scaled Scores and Performance Levels. Scaled Scores are the number of correct answers converted to a common scale so that achievement can be compared across grade levels. Performance Levels are four proficiency levels that show how students have mastered the knowledge and skills that make up the learning standards

Source: New York City Department of Education, "Scaled Score and Performance Levels," report posted online at http:/schools.nyc.gov/daal. 
Appendix Table 1

Correlations among Charter School Policies and Practices

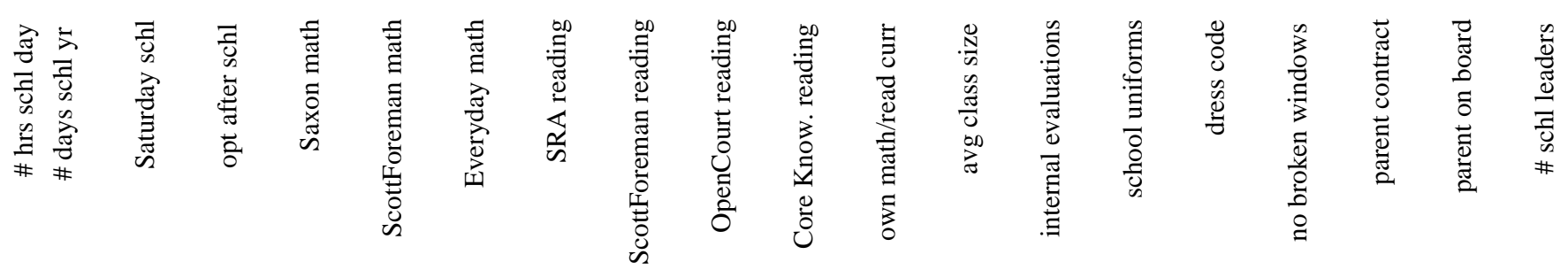

number of hours in school day 1

number of days in school year $\quad 0.57$

Saturday school

optional after-school

Saxon math

Scott Foresman math

Everyday math

SRA reading

Scott Foresman reading

Open Court reading

Core Knowledge reading

own math/reading curriculum

average class size

internal evaluations

school uniforms

dress code

No Broken Windows

parent contract

parent on board

number of school leaders

0

$-0.4$

\section{7}

$\begin{array}{llll}-0.4 & -0.3 & 0.1 & 1\end{array}$

$\begin{array}{lllll}0.13 & 0.14 & 0 & 0.1\end{array}$

$\begin{array}{llllll}0 & -0.2 & -0.3 & 0.16 & -0.2 & 1\end{array}$

0.14

0.29

0.65

0.36

$-0.2$

0.35

0.57

0.3

chool leaders

after-school programing. Note that some variables are continuous (numbers of hours in the school day and so on). Source: charter school descriptions. 